\title{
Spectral and Polarimetric Imagery Collection Experiment (SPICE) Longwave Infrared Spectral Dataset
}

by Dalton Rosario, Joao Romano, and Christoph Borel-Donohue

ARL-TR-7051

September 2014 


\section{NOTICES}

\section{Disclaimers}

The findings in this report are not to be construed as an official Department of the Army position unless so designated by other authorized documents.

Citation of manufacturer's or trade names does not constitute an official endorsement or approval of the use thereof.

Destroy this report when it is no longer needed. Do not return it to the originator. 


\title{
Army Research Laboratory
}

Adelphi, MD 20783-1138

\section{Spectral and Polarimetric Imagery Collection Experiment (SPICE) Longwave Infrared Spectral Dataset}

\author{
Dalton Rosario \\ Sensors and Electron Devices Directorate, ARL \\ Joao Romano \\ US Army Armament Research Development Engineering Center (ARDEC) \\ Picatinny Arsenal, NJ \\ Christoph Borel-Donohue \\ US Air Force Institute of Technology (AFIT) \\ Wright Patterson Air Force Base, $\mathrm{OH}$
}




\section{REPORT DOCUMENTATION PAGE}

Form Approved OMB No. 0704-0188

Public reporting burden for this collection of information is estimated to average 1 hour per response, including the time for reviewing instructions, searching existing data sources, gathering and maintaining the data needed, and completing and reviewing the collection information. Send comments regarding this burden estimate or any other aspect of this collection of information, including suggestions for reducing the burden, to Department of Defense, Washington Headquarters Services, Directorate for Information Operations and Reports (0704-0188), 1215 Jefferson Davis Highway, Suite 1204, Arlington, VA 22202-4302. Respondents should be aware that notwithstanding any other provision of law, no person shall be subject to any penalty for failing to comply with a collection of information if it does not display a currently valid OMB control number.

PLEASE DO NOT RETURN YOUR FORM TO THE ABOVE ADDRESS.

\begin{tabular}{|l|l|l|l} 
1. REPORT DATE (DD-MM- $Y Y Y Y)$ & 2. REPORT TYPE & 3. DATES COVERED (FrOm - To)
\end{tabular}

\begin{tabular}{l|l} 
September 2014 & Final
\end{tabular}

4. TITLE AND SUBTITLE

Spectral and Polarimetric Imagery Collection Experiment (SPICE) Longwave

Infrared Spectral Dataset

October 2013 to September 2014

5a. CONTRACT NUMBER

5b. GRANT NUMBER

5c. PROGRAM ELEMENT NUMBER

6. AUTHOR(S)

Dalton Rosario, Joao Romano, and Christoph Borel-Donohue

5d. PROJECT NUMBER

5e. TASK NUMBER

5f. WORK UNIT NUMBER

8. PERFORMING ORGANIZATION

REPORT NUMBER

US Army Research Laboratory

ATTN: RDRL-SES-E

ARL-TR-7051

2800 Powder Mill Road

Adelphi, MD 20783-1138

9. SPONSORING/MONITORING AGENCY NAME(S) AND ADDRESS(ES)

10. SPONSOR/MONITOR'S ACRONYM(S)

11. SPONSOR/MONITOR'S REPORT

NUMBER(S)

12. DISTRIBUTIONIAVAILABILITY STATEMENT

Approved for public release; distribution unlimited.

13. SUPPLEMENTARY NOTES

14. ABSTRACT

This report summarizes our observations using the longwave infrared (LWIR) hyperspectral data subset of the Spectral and Polarimetric Imagery Collection Experiment (SPICE) dataset, which emphasizes the inherent challenges associated with applying autonomous spectral pattern recognition methods to LWIR hyperspectral imagery, as well as data quality and qualitative validation of expected atmospheric spectral features. SPICE is a collaborative effort between the US Army Research Laboratory, US Army Armament Research, Development, and Engineering Center, and the US Air Force Institute of Technology. It focused on the long-term LWIR hyperspectral and polarimetric data collection of a target site, under various weather and non-ideal conditions, and exploitation of this dataset for pattern recognition tasks. We concluded from this effort that the quality of SPICE hyperspectral LWIR data is categorically comparable to other datasets recorded by a different sensor of similar specifications and is adequate for algorithmic research. The vast dataset and associated ground-truth information are a great asset for research.

15. SUBJECT TERMS

Longwave infrared, LWIR hyperspectral, dataset, temperature and emissivity separation, radiometric calibration, SPICE

\begin{tabular}{|l|l|l|l|l|l|}
\hline \multicolumn{2}{|l|}{ 16. SECURITY CLASSIFICATION OF: } & $\begin{array}{l}\text { 17. LIMITATION } \\
\text { OF } \\
\text { ABSTRACT }\end{array}$ & $\begin{array}{l}\text { 18. NUMBER } \\
\text { OF } \\
\text { PAGES }\end{array}$ & $\begin{array}{l}\text { 19a. NAME OF RESPONSIBLE PERSON } \\
\text { Dalton Rosario }\end{array}$ \\
\cline { 1 - 2 } $\begin{array}{c}\text { A. Report } \\
\text { Unclassified }\end{array}$ & $\begin{array}{l}\text { b. ABSTRACT } \\
\text { Unclassified }\end{array}$ & $\begin{array}{l}\text { c. THIS PAGE } \\
\text { Unclassified }\end{array}$ & UU & 50 & $\begin{array}{l}\text { 19b. TELEPHONE NUMBER (Include area code) } \\
\text { (301) 394-4235 }\end{array}$ \\
\hline
\end{tabular}

Standard Form 298 (Rev. 8/98) Prescribed by ANSI Std. Z39.18 


\section{Contents}

List of Figures $\quad$ iv

Executive Summary vii

$\begin{array}{lr}\text { 1. Introduction } & 1\end{array}$

2. Data Collection and Sensor Characterization 2

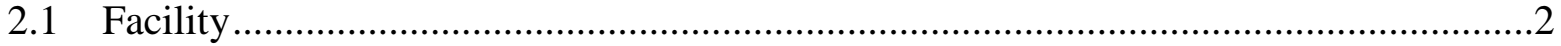

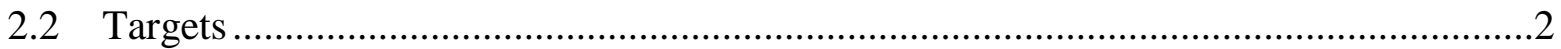

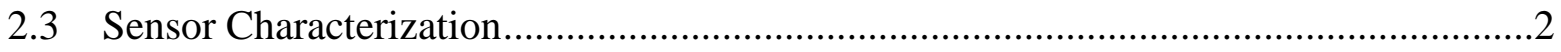

2.4 Temperature Emissivity Retrieval Problem and Algorithm....................................6

2.4.1 Previous Temperature-emissivity Separation Algorithm ..................................7

2.4.2 ARTEMISS Summary of Improvements ......................................................

2.5 Qualitative Data Assessment.................................................................................11

$\begin{array}{lr}3 . & \text { Conclusions }\end{array}$

4. Future Plans $\quad 31$

5. References $\quad 32$

List of Symbols, Abbreviations, and Acronyms

$\begin{array}{ll}\text { Distribution List } & 36\end{array}$ 


\section{List of Figures}

Fig. 1 Telops LWIR Hyper-Cam’s basic specs .................................................................3

Fig. 2 Illustration of the indoor setting used at AFIT to test and validate performance of both the ARL- and AFIT-owned LWIR Hyper-Cams.

Fig. 3 Data processing flow of the radiometric calibration method applied to Telops Hyper-

Cam raw data

Fig. 4 Effect of channeling in spectral data recorded by the Telops Hyper-Cam; the spectral ripple (noise), although embedded in the data, does not significantly change the predominant underlying spectral characteristics observed in the illustrated spectrum (red box highlighting the spectral feature in the top image)

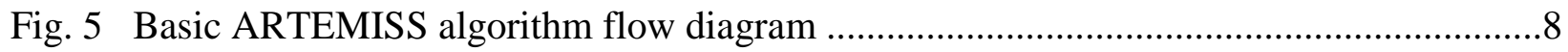

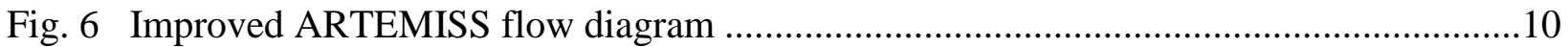

Fig. 7 New ARTEMISS algorithm based on iterative retrieval of the atmosphere based on the AMOEBA algorithm followed by the fast three-band ratio technique (CIBR) to retrieve temperature

Fig. 8 Typical AFIT calibration/TES code’s diagnostic output using SPICE LWIR hyperspectral data

Fig. 9 Example of daytime partly cloudy condition; downwelling radiance is a mixture of Planck's blackbody radiance from the clouds and clear sky. The color code corresponds to color-box-highlighted objects in the scene, plot colors, and colored object-name fonts. The spectral interval of the sensor's operation under specs is between 8.0 and 11.5 micron.

Fig. 10 (Top) Example of night and cloudy conditions; downwelling radiance matches the environment, which is at the same temperature. (Bottom) Example of daytime cloudy conditions; clouds behave like a blackbody when the environment is hotter than cloud temperature. (The color code corresponds to the same one in Fig. 12.) The spectral interval under specs is between 8.0 and 11.5 micron.

Fig. 11 (Top) Example of a thermal cross-over; downwelling radiance matches the environment and all surfaces have the same temperature. (Bottom) Example of daytime clear and hot conditions; trees show a Planck’s blackbody radiance, surrogate tanks are hotter than environment and show absorption features, and sky plate reflects cold sky. (The color code corresponds to the same one in Fig. 9.) The spectral interval under specs is between 8.0 and 11.5 micron. 
Fig. 12 (Left) Single band image (of the same scene shown in Fig. 8) depicting data blocks used to estimate the average mean spectra of spatially apart objects in the scene; some of these objects have the same material type. Surrogate targets: red region ( $0^{\circ}$ aspect angle), green area (same paint/tank posed at $90^{\circ}$ ), and dark blue area (same paint/tank posed at $135^{\circ}$ ). Vegetation trees: yellow and dark magenta (upper right) area. Sparse grass and soil: light blue area. Dirt/pebble road: magenta area (far left middle). (Right) Sample average spectral profiles representing selected spatial areas in the scene shown in the lefthand side image; spectra within each color area were the only ones used to produce the average spectral profile per color area. The plot color code corresponds to the same one in the left image.

Fig. 13 Illustration of spectral profiles of different material types at the ARDEC SPICE site, where (left) data from the AFIT-owned Hyper-Cam were collected in July 2011 and (right) data from the ARL-owned Hyper-Cam were collected a year later in July 2012 ........18

Fig. 14 MODTRAN models: MWIR/LWIR diffuse downwelling radiance as a function of atmospheric conditions

Fig. 15 MODTRAN vs. real measurements of the downwelling sky radiance analysis using the AFIT-owned Hyper-Cam, where such a validation was needed for the development of the QTES code....

Fig. 16 (Top) MWIR/LWIR diffuse downwelling radiance as a function of cloud conditions. (Bottom) LWIR downwelling radiance measurements for different cirrus cloud thicknesses compared to clear sky and liquid clouds...

Fig. 17 Spectra from the same object (target T0) and approximate pixel location on the target, both collected by two independent Hyper-Cams (AFIT vs. ARL) a year apart (July 2011 and July 2012). The strong oscillation patterns between 8.0 and $9.4 \mu \mathrm{m}$ are due to water vapor concentration in the atmosphere between the target surface and the sensor. Oscillation amplitude is also impacted by the humidity level in the atmosphere. The target (surrogate howitzer) was hotter during AFIT data acquisition and spectral absorptions appear stronger because of its finer spectral resolution than ARL's data. Distinct spectral patterns in both spectra are clearly visible between 9.4 and $11.0 \mu \mathrm{m}$ using both sensors a year apart are encouraging. (The spectrum from the AFIT sensor was sub-sampled from 206 to 103 bands - the number of bands recorded by the ARL sensor, as described in text, so both spectra could be plotted in the same graph.)

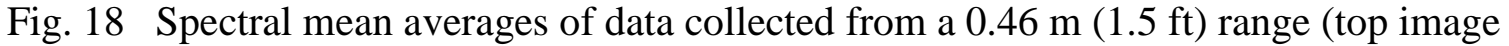
and a $570 \mathrm{~m}(1,870 \mathrm{ft})$ range (bottom image), using the SPICE LWIR Hyper-Cam to collect data of the same material (green paint on the surrogate howitzer target). Due to many factors, spectral differences are expected to exist, given the large difference in range, to include reflection of emitted downwelling sky radiance off the target at far ranges (which is blocked by the sensor's physical presence at close range), and a significantly higher concentration of atmosphere between target and sensors.

Fig. 19 Examples of individual spectrum of the same target recorded in three different years: July 2011 (AFIT sensor), July 2012 (ARL sensor), and July 2013 (ARL sensor) from two ranges $(0.46$ and $570 \mathrm{~m})$. Among other factors, the cumulative concentration of water vapor in the atmosphere, which increases as a function of range, plays a major role in changing the spectral profile of the target.

Fig. 20 Selected number of band-averaged images of the same target site during two complete diurnal cycles on 22-23 July 2012 ....... 
INTENTIONALLY LEFT BLANK. 


\section{Executive Summary}

This technical report summarizes our observations using the longwave infrared (LWIR) hyperspectral data subset of the Spectral and Polarimetric Imagery Collection Experiment (SPICE) dataset, which emphasizes the inherent challenges associated with using the LWIR region of the electromagnetic spectrum and hyperspectral sensing modality for applying autonomous spectral pattern recognition methods to imagery acquired by corresponding remote sensing cameras, as well as data quality, qualitative validation of expected atmospheric spectral features, and qualitative comparison against another dataset of the same site using a different LWIR hyperspectral sensor.

SPICE is a collaborative effort between the US Army Research Laboratory (ARL), US Army Armament Research, Development, and Engineering Center, and more recently, the US Air Force Institute of Technology. It focused on the collection and exploitation of LWIR hyperspectral and polarimetric imagery.

We concluded from this effort that the quality of SPICE hyperspectral LWIR data is categorically comparable to other datasets recorded by a different sensor of similar specifications and is adequate for algorithm research, given the scope of SPICE.

The scope was set to use both sensing modalities to conduct a long-term LWIR data collection of the same site, consisting of multiple distinct material types (manmade and natural), under various weather and non-ideal conditions. Using the vast dataset and associated ground-truth information, our near future plan is to assess performance of the state-of-the-art algorithms, and more importantly, determine performance degradation sources from this assessment, to include unrealistic data assumptions.

Our expectation is that results from this assessment will spur new and more realistic algorithmic ideas that could reach beyond the region of the spectrum and sensing modalities used in the SPICE effort. This is likely to significantly augment the performance of autonomous pattern recognition methods for remote sensing applications.

We are confident that over time the SPICE dataset will prove to be an asset to ARL, its partners, and the wider open scientific community. Of course, this optimism should not undermine the amount of work that lies ahead using an unprecedented database of over 25,000 LWIR hyperspectral data cubes. 
INTENTIONALLY LEFT BLANK. 


\section{Introduction}

Detection and identification of military and civilian targets from airborne platforms using hyperspectral sensors is of great interest. Relative to broadband or multispectral sensing, hyperspectral sensing can increase the detectability of pixel and subpixel size targets by exploiting finer detail in the spectral signatures of targets and natural backgrounds.

A multitude of adaptive detection and recognition algorithms have appeared in the literature or have found their way into software packages and end-user systems: algorithms for resolved and subpixel targets with known or unknown spectral characterization, in a background with known or unknown statistics, that are theoretically justified or ad hoc, and with low or high computational complexity

But despite the high activity level of the past two decades, which can be measured by the high number of publications produced by researchers in the geosciences and remote sensing community, during which new autonomous algorithms with promises of better performance were proposed, a sizeable percentage of researchers in this community seem now convinced that the pattern recognition problem will not be solved by purely relying on human innovation and idealized mathematical concepts.

Data are needed and are indispensible, especially, if the interest is to assess the value of exotic sensing modalities, such as hyperspectral or polarimetric, for material pattern recognition in remote sensing applications.

The US Army Research Laboratory (ARL) and the US Army Armament Research, Development, and Engineering Center (ARDEC) have heeded this data plea from the target community and are acted on it. The result became known as the Spectral and Polarimetric Imagery Collection Experiment (SPICE). SPICE is a collaborative effort between ARL, ARDEC, and more recently, the US Air Force Institute of Technology (AFIT) that focuses on the longwave infrared (LWIR) hyperspectral and polarimetric sensing modalities. SPICE is aimed at collecting a comprehensive dataset of both sensing modalities spanning multiple years in order to capture sensor performance in a wide variety of meteorological (MET) conditions, focusing on the diurnal and seasonal changes inherent to a northeastern region of the United States. A portion of the dataset is planned to be made public release in the future in order to enable unrestricted dissemination of it to the wider open scientific community for algorithmic research and development (R\&D).

In this report, we present some results from our first observations of the LWIR hyperspectral data subset of SPICE. (Results have been published using the LWIR polarimetric data subset of SPICE. ${ }^{1,2}$ ) Our focus in this report is to discuss the inherent challenges associated with using the SPICE LWIR hyperspectral dataset for the purpose of pattern recognition, as well as consider 
data quality, qualitative validation of expected atmospheric spectral features, and qualitative comparison against another dataset of the same site using a different LWIR hyperspectral sensor.

The SPICE database contains over 25,000 LWIR hyperspectral data cubes, of which only a very small but well-selected sample of it has been used for the work presented in this report.

\section{Data Collection and Sensor Characterization}

\subsection{Facility}

The SPICE facility allows for a sensor altitude of $126 \mathrm{~m}$ with respect to the target placement site, which is located at a slant range of $570 \mathrm{~m}$ out from the tower base used to house the sensors. Being located in the northeastern region of the United States, various adverse weather conditions are experienced at the target site throughout the year. Expected weather conditions include light to heavy rain, light to heavy fog, as well as various types of cloud cover, various snow types, and different humidity levels. To accurately determine and characterize these adverse weather conditions and help aid in the measurement of the propagation path attenuation, the tower is equipped with a fully automated onsite MET data collection system composed of various basic and advanced MET sensors at both the target site and tower. All MET instrumentations are connected to a networked data logger located at the base tower, which allows for autonomous ground-truth data collection. The MET data are archived and can be retrieved for future analysis at a later time. Also a subset of the MET data is included in the header of calibrated imagery. LWIR and midwave infrared (MWIR) signal propagation is certainly affected by adverse weather conditions that occur during data collection; hence, maintaining an accurate account of these conditions is vital for characterization and analysis of the dataset.

\subsection{Targets}

The use of actual operational military vehicles as targets to support the continuous and automatic nature of a long-term data collection at the tower proved to be too expensive, thus, surrogate Russian 2S3 howitzers were used instead. The 2S3 surrogate targets provide reasonably validatable broadband infrared signatures, which were accomplished by producing a physical replication of the actual vehicle using a similar metallic construction and paint, and adding supplemental heated surfaces. The supplemental heated surfaces mimic the characteristics of an operational howitzer (idling or gun firing). Three 2S3 surrogates were located at the target site and were oriented in aspect angles of $0^{\circ}, 90^{\circ}$, and $135^{\circ}$ (counterclockwise) with respect to the sensors (shown later in the upper-right portion of Fig. 8).

\subsection{Sensor Characterization}

The hyperspectral sensor used in SPICE is a commercially available Fourier-transform spectrometer LWIR imager that requires cooling to $65 \mathrm{~K}$ to achieve a typical noise equivalent 
spectral radiance (NESR) of $20 \mathrm{nW} / \mathrm{cm}^{2} \mathrm{sr} \mathrm{cm}^{-1}$ for a nominal $300 \mathrm{~K}$ blackbody radiance. Its 320x256 LWIR photovoltaic mercury cadmium telluride (PV MCT) focal plane array (FPA) detectors are particularly sensitive to thermal radiance between 8 and 11.5 micron, by design specification, and the spectral resolution is user selectable from 0.25 to $150 \mathrm{~cm}^{-1}$. The sensor was manufactured by the Canadian company Telops (Quebec), using system components from other international vendors, in particular, Sofradir of France, which manufactured the FPA. The sensor is known as LWIR Hyper-Cam. Additional specifications are provided in Fig. 1.

- Product launched in 2004

- Imaging Spectrometer

- Commercial Off-the-Shelf (COTS)

- Fourier Transform Technology - LWIR: 8-12 $\mu \mathrm{m}$

- MWIR: 3-5 $\mu \mathrm{m}$

- MWIR-E: $1.5-5.5 \mu \mathrm{m}$

- $320 \times 256$ pixels (Cooled FPA)

- IFOV of 0.35 mrad

- Adjustable spectral resolution: - $0.25-150 \mathrm{~cm}^{-1}$

- Real-time calibrated spectra

- Boresight camera

- Portable $(29 \mathrm{~kg})$

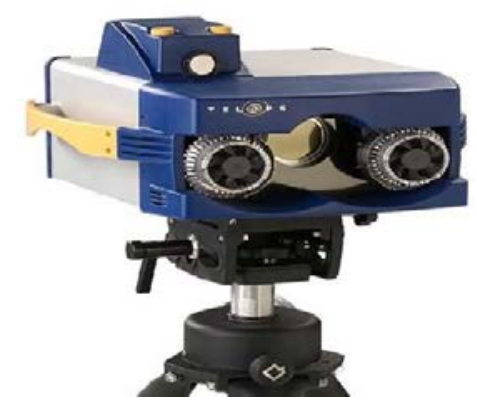

Fig. 1 Telops LWIR Hyper-Cam’s basic specs

In the last 15 years, Telops’ LWIR Hyper-Cam (previously known as LWIR FIRST) has become popular in the scientific community because of its commercial availability, affordability, reasonable performance, and unrestricted status under the American and Canadian International Traffic in Arms Regulations (ITAR). Accordingly, the LWIR Hyper-Cam is based on a starring rather than pushbroom hyperspectral system. ${ }^{3}$

The software for the LWIR Hyper-Cam used in SPICE was uniquely configured to allow continuous and programmable data collection and a remote control capability via an Intranet or Internet network. These capabilities, however, do not eliminate the challenges associated with conducting an automatic and continuous data collection effort over all kinds of atmospheric and environmental conditions (cloudy, raining, snowing, cold, hot, etc.). As such, one must decide on an ad-hoc basis what settings to use to meet the desired critical parameters. Examples of these parameters are spectral resolution, integration time, focus, and temperature interval between both blackbodies that would embrace as narrowly as possible all possible material temperatures in the scene. These settings are critical in order to achieve acceptable data quality results, both daytime and nighttime. As of March 2014, the SPICE database contains over 25,000 uncalibrated LWIR hyperspectral data cubes, where $100 \%$ of this dataset is radiometrically calibrated at ARL using calibration code by Borel et al. ${ }^{4}$

We performed a basic assessment of the LWIR Hyper-Cam used in SPICE for a period of 30 days at AFIT before the data collection started at ARDEC and compared basic performance against another specs-similar imager. (In order to distinguish between the two imagers, we refer 
to the instrument used in SPICE as the “ARL-owned sensor” or “ARL LWIR Hyper-Cam.”) In particular, we performed characterization of the ARL LWIR Hyper-Cam at the AFIT Remote Sensing Laboratory, a well-equipped sensor calibration/characterization facility, and compared its results against results produced by another Telops LWIR Hyper-Cam owned by AFIT. (The AFIT-owned Hyper-Cam is similar to the ARL-owned Hyper-Cam.)

Both sensors were employed in the same indoor lab and limited outdoor experimentations. For the test, we used a few distinct material types of known emissivity under a surface temperature controlled setting (Fig. 2).

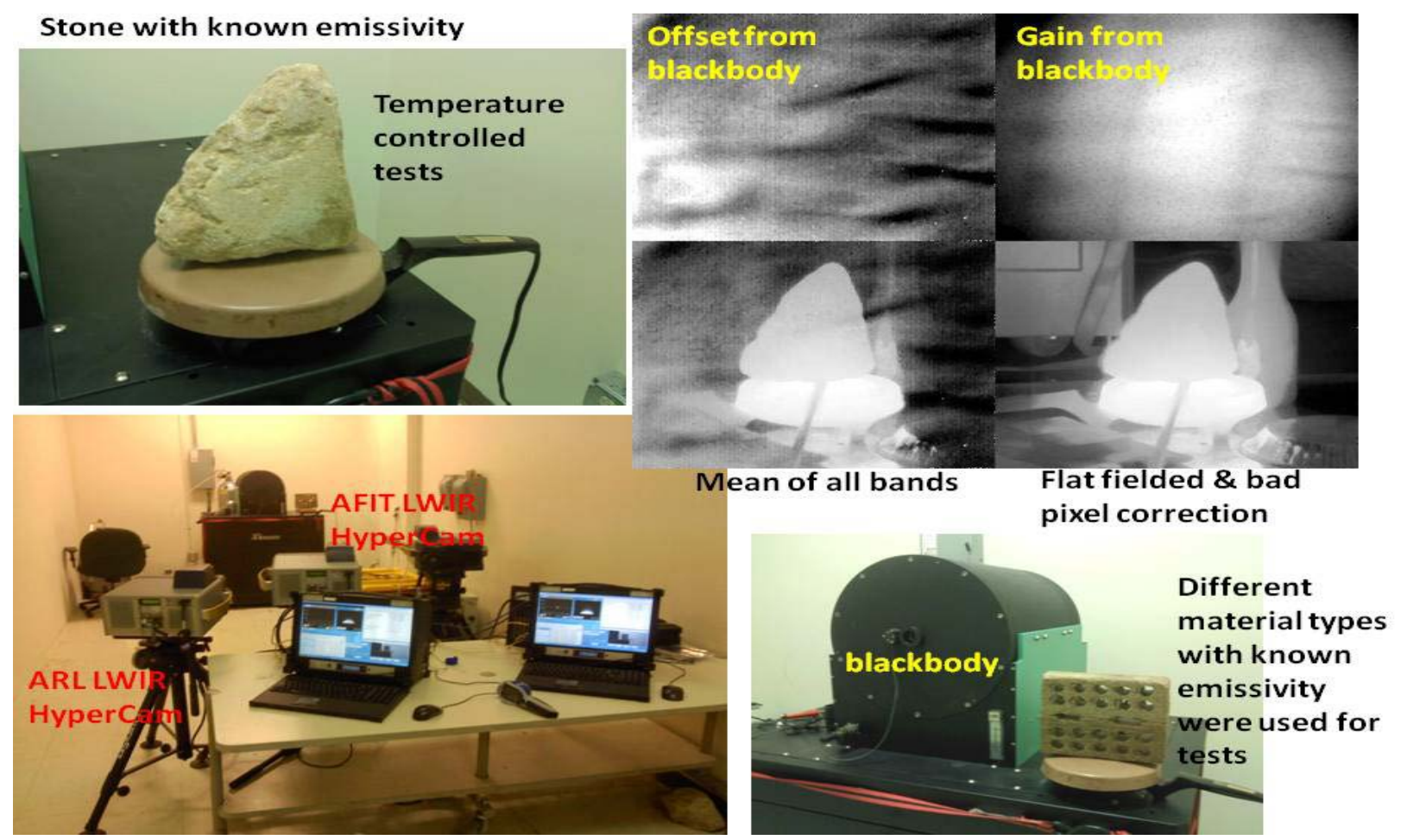

Fig. 2 Illustration of the indoor setting used at AFIT to test and validate performance of both the ARL- and AFITowned LWIR Hyper-Cams

Figure 2 depicts both sensors imaging an indoor scene consisting of natural stones of known emissivity values and a large blackbody (among other material types), where the temperature of these material types were measured and adjusted accordingly to different desired values as part of the experimentation. Figure 2 also shows an illustration of output images produced at different stages of the data processing method applied to raw data (interferogram) from the scene. Figure 2 and the flowchart in Fig. 3 show two blackbodies (BB1 and BB2) directly attached to the HyperCams (both ARL's and AFIT's), which were allowed to move (software-controlled movement) immediately in front of the sensor optics so blackbody raw data could be recorded at zero range and used later to perform radiometric calibration of the scene data. During the scene data collection, BB2 was set to a temperature value lower than the lowest material temperature in the scene and BB1 was set to a temperature value higher than the highest material temperature in the 
scene. Details on the method depicted in Fig. 3, where QTES denotes Quick Temperature and Emissivity Separation, have been published elswhere ${ }^{4}$ and are summarized in Section 2.4. (The method depicted in Fig. 3 is the same one applied to the raw data recorded by both ARL- and AFIT-owned LWIR Hyper-Cams.)

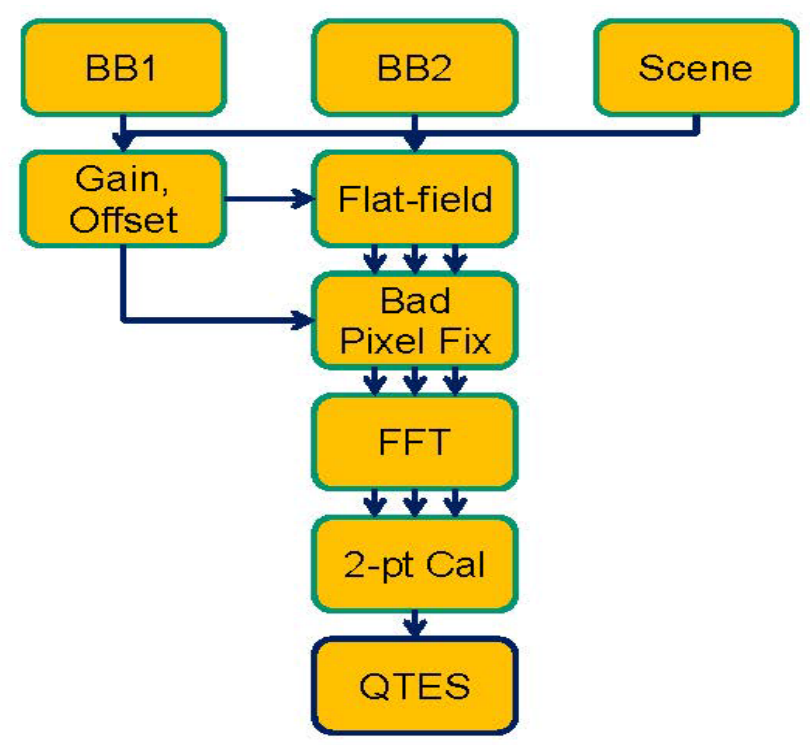

\section{Data flow:}

1. Flat-field calibrations (BB1, BB2) and scene cube

2. Find and fix bad pixels

3. Perform FFT

4. Perform 2-point calibrations on raw spectra
5. Retrieve temperature and emissivity with QTES

Fig. 3 Data processing flow of the radiometric calibration method applied to Telops Hyper-Cam raw data

After analysis of results from the experiments performed at AFIT, we concluded that the experiment results produced by the ARL-owned Hyper-Cam were comparable to the results produced by the AFIT-owned Hyper-Cam, and noted that the data quality produced by these sensors is as good as one can expect using the technology employed by Telops to manufacture these sensors, i.e., FPA of PV MCT detectors cooled to $65 \mathrm{~K}$. We also confirmed that the data produced by the LWIR Hyper-Cam are noisier (Fig. 4) than some other datasets collected with far more expensive sensors, citing as an example the US Air Force sponsored SEBASS LWIR hyperspectral instrument, which requires cooling the FPA of silicon arsenide (SiAs) impurityband-conduction detectors to less than $10 \mathrm{~K}^{5}$

Channeling, from when the device passed through the radiometric calibration process, caused a spectral ripple (noise) observed in the data recorded by the Telops Hyper-Cam. However, the resulting spectral ripple does not seem to significantly change the predominant underlying characteristics of observed spectra, as shown in Fig. 4 (top image: the red box highlights the spectral characteristics undisturbed by noise), specifically, the manmade and natural objects as opposed to the gases. 


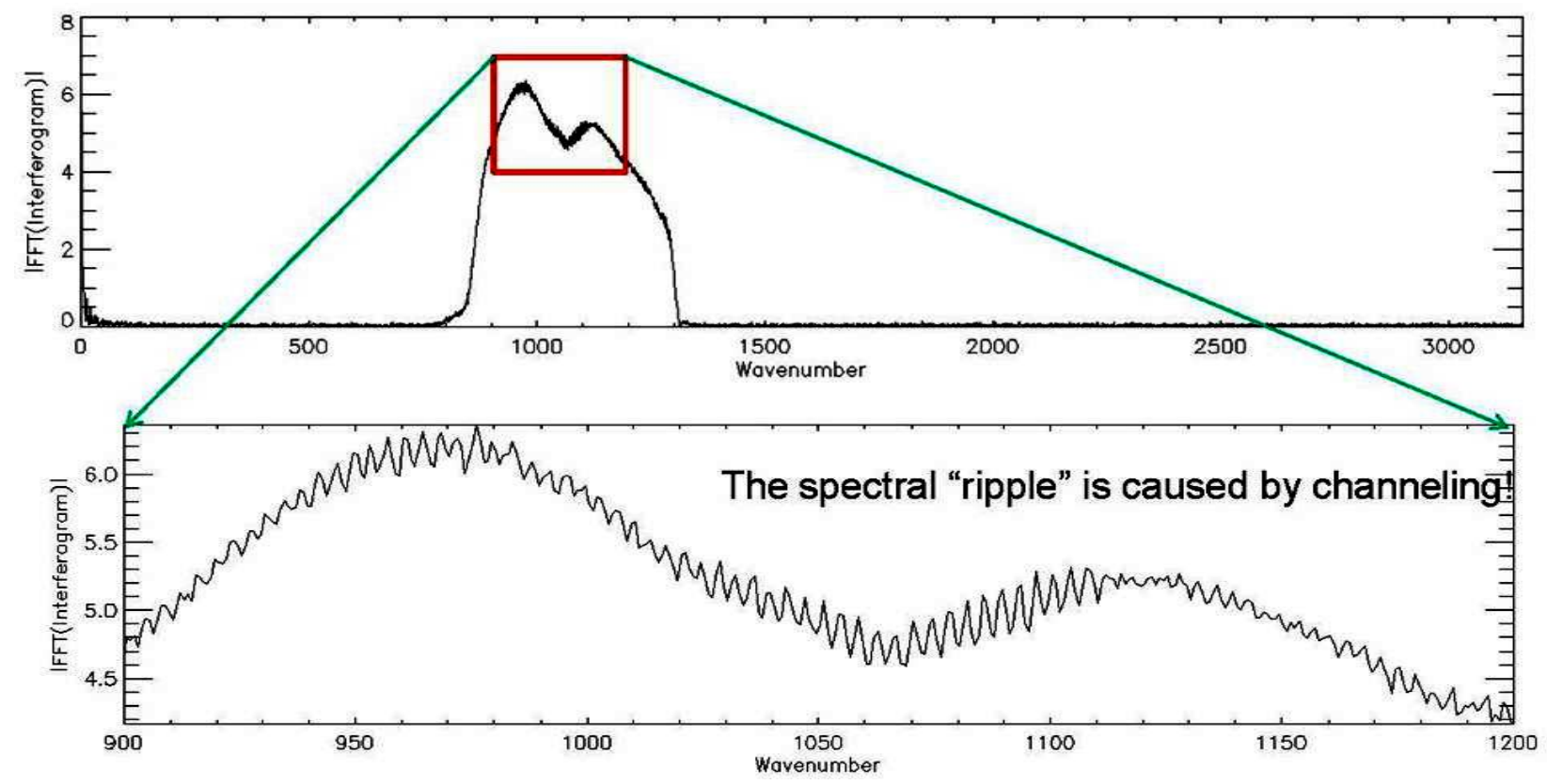

Fig. 4 Effect of channeling in spectral data recorded by the Telops Hyper-Cam; the spectral ripple (noise), although embedded in the data, does not significantly change the predominant underlying spectral characteristics observed in the illustrated spectrum (red box highlighting the spectral feature in the top image)

Also, as expected, internal energy reflection due to plane parallel surfaces inside a sensor yields both constructive and destructive interferences; and, accordingly, when constructive interference in particular occurs (i.e., when the phase difference between two waves is a multiple of $2 \pi$ ), the phenomenon will usually cause channeling (Fig. 4). As mentioned earlier, the effect of channeling is the spectral ripple, or noise, in the spectral domain.

\subsection{Temperature Emissivity Retrieval Problem and Algorithm}

The central problem of temperature-emissivity separation ${ }^{7}$ is that given $N$ spectral measurements of radiance, one needs to find $N+1$ unknowns ( $N$ emissivities and one temperature). In the past, several methods were proposed:

1. Assumed channel 6 emittance model ${ }^{8}$

2. Emissivity Spectrum Normalization (ESN) ${ }^{7}$

3. Thermal log and alpha residual ${ }^{9}$

4. Mean-maximum difference (MMD) ${ }^{10}$

These algorithms were developed to retrieve surface emissivity and temperature from multispectral data.

To analyze hyperspectral thermal data, it is necessary to correct the data for atmospheric effects in order to retrieve surface emissivity and temperature. This process is commonly called 
temperature-emissivity separation (TES), and only a few algorithms exist for hyperspectral data. The following algorithms are known to us:

1. In-scene atmospheric correction (ISAC) algorithm ${ }^{11,12}$

2. Autonomous atmospheric compensation ${ }^{13}$

Using hyperspectral data has the advantage of having more bands than necessary and thus it might be possible to find solutions for the unknowns, although uniqueness is not guaranteed.

\subsubsection{Previous Temperature-emissivity Separation Algorithm}

It was found that by varying the atmospheric parameters, such as water vapor, atmospheric temperature and surface temperature (the latter in small steps), the emissivity could be estimated. ${ }^{14}$ When the surface temperature is correctly retrieved, the emissivity is spectrally smooth, that is, it shows no presence of atmospheric features. The observation that surface emissivities ${ }^{15}$ tend to be much smoother than atmospheric transmission features was very important in the development of a hyperspectral TES algorithm.

After several years, the basic TES algorithm ${ }^{16}$ that was improved as part of this work, namely, the Automatic Retrieval of Temperature and Emissivity using Spectral Smoothness (ARTEMISS), was developed as shown in Fig. 5. It is based on three steps:

1. The ARTEMISS In-Scene Atmospheric Compensation (ARTISAC) method estimates the atmospheric transmission.

2. The ARTISAC estimated transmission is compared to a database (transmission, up-welling, downwelling radiance [TUD]-look-up table [LUT]) of atmospheres computed using Moderate Resolution Atmospheric Transmission (MODTRAN), ${ }^{6}$ and the closest matches are evaluated and ranked as candidate atmospheres. The best candidate is chosen by a pixel voting scheme.

3. The modeled at-sensor radiance is computed using a spectrally smooth emissivity. By minimizing the difference between measured and modeled radiance, ARTEMISS produces three outputs: a temperature image $T(x, y)$, an emissivity cube $\varepsilon(\lambda, x, y)$, and a root mean square error (RMSE) radiance fitting error $\sigma(x, y)$. 


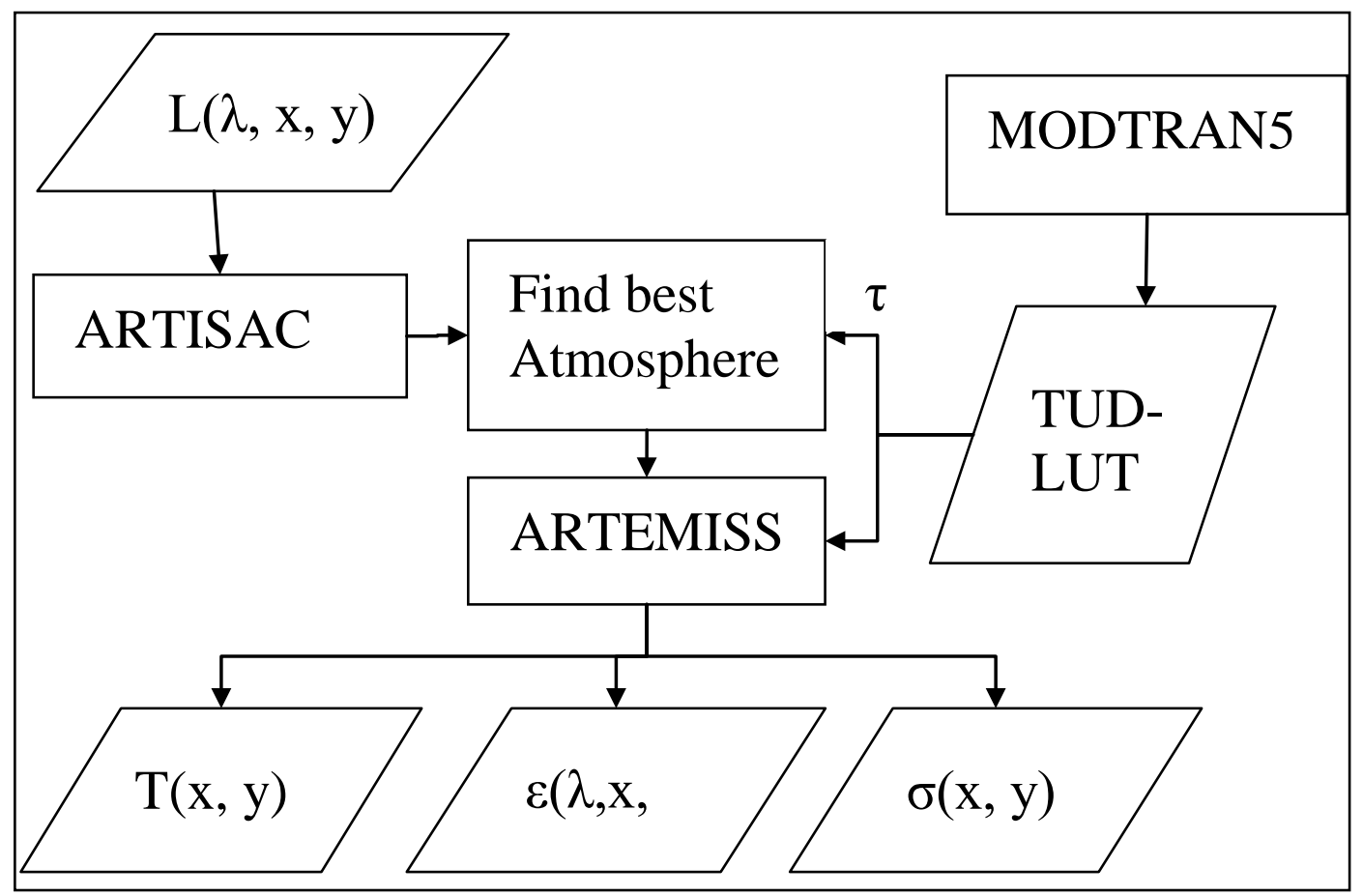

Fig. 5 Basic ARTEMISS algorithm flow diagram

The measured radiance $L_{\text {measured }}(\lambda)$ can be written as

$$
L_{\text {measured }}(\lambda)=L_{\text {ground }}(\lambda)+L_{\text {path }}(\lambda),
$$

where the ground-leaving radiance $L_{\text {ground }}(\lambda)$ is given by

$$
\begin{aligned}
L_{\text {ground }}(\lambda)=[ & \left.\varepsilon(\lambda) B\left(\lambda, T_{\text {ground }}\right)\right] \tau_{\text {atmo }}(\lambda) \\
& +[1-\varepsilon(\lambda)] L_{\text {down }}(\lambda),
\end{aligned}
$$

and the path radiance $L_{\text {path }}(\lambda)$ is given by

$$
L_{p a t h}(\lambda)=\left[1-\tau_{\text {atmo }}(\lambda)\right] B\left(\lambda, T_{a t m o}\right),
$$

where $\varepsilon(\lambda)$ is the spectral emissivity, $\tau_{a t m o}(\lambda)$ is the transmission from the ground to the sensor, $B(\lambda, T)$ is the Planck blackbody function, and $T_{x}$ is a temperature. Equation 1 can be solved for the emissivity as

$$
\varepsilon=\frac{L_{m}-L_{p}-L_{d}}{B\left(\lambda, T_{e s t}\right) \tau-L_{d}}
$$

where the estimated ground temperature $T_{\text {est }}$ is given by

$$
T_{\text {est }}=B^{-1}\left(\lambda_{0}, \frac{L_{m}-L_{p}-\left(1-\varepsilon_{0}\right) L_{d}}{\varepsilon_{0} \tau}\right) .
$$


where $\lambda_{0}$ is arbitrary selected to be $10 \mu \mathrm{m}$, atmospheric absorption is small, and transmittance is large. The "best" temperature, $T_{o p t}$, is found by minimizing the RMSE of the difference between the measured radiance and a fitted radiance $L_{f i t}$ :

$$
T_{\text {opt }}=\min \left[\sigma\left\{L_{m}-L_{\text {fit }}\right\}\right]
$$

where $L_{f i t}$ is given by

$$
L_{f i t}\left(T_{o p t}, \varepsilon_{o p t}\right)=\bar{\varepsilon}_{o p t} B\left(\lambda, T_{o p t}\right) \tau+\left(1-\bar{\varepsilon}_{o p t}\right) L_{d}+L_{p}
$$

The $\bar{\varepsilon}_{\text {opt }}$ is the three-point smoothed emissivity from Eq. 4.

\subsubsection{ARTEMISS Summary of Improvements}

Recent developments have improved code performance in both accuracy and speed. The ARTISAC method has been refined to produce transmission estimates using only certain pixels. The matching of the estimated transmission to a TUD-LUT database is still available and has been parallelized using message passing interface (MPI) software, which reduces the TUD-LUT generation time significantly when a cluster of computers is available. The atmospheric parameters that are varied for the TUD-LUT are 1) an atmospheric temperature offset, 2) a water vapor scaling factor, and 3) an ozone scaling factor. The need to generate a large TUD-LUT has been made unnecessary by the development of a two-step process. The first step is a coarse retrieval of the effective atmospheric temperature, columnar water vapor amount, and ozone. This can be done using a small-size TUD-LUT (a $3 \times 3 \times 3$ or $5 \times 5 \times 5$ is usually adequate) and a library matching method, or by using the inverse Planck blackbody function to estimate the atmospheric temperature coupled with various atmospheric absorption features to estimate water vapor and ozone.

Figure 6 shows how these improvements fit into the basic ARTEMISS algorithm. 


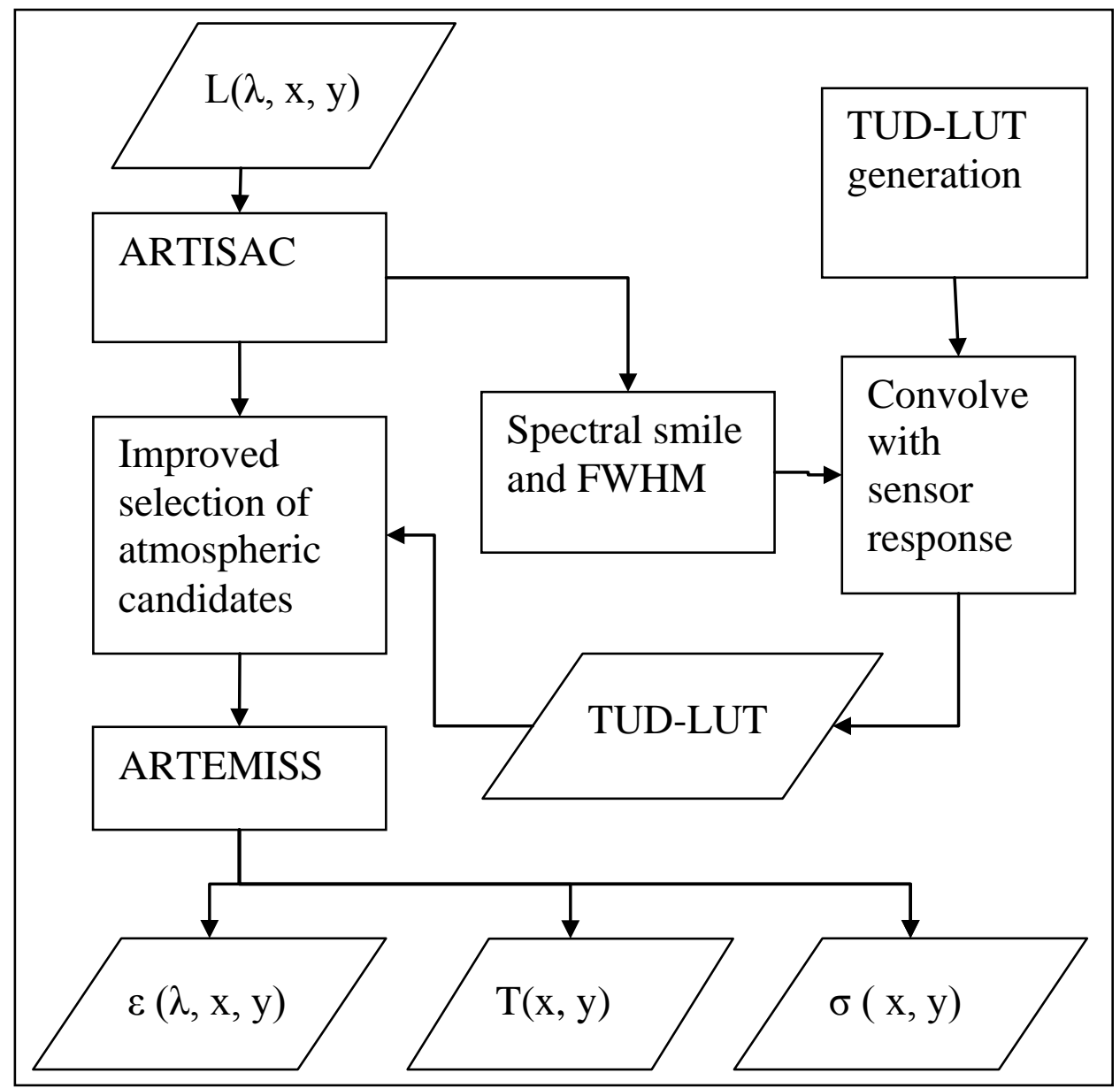

Fig. 6 Improved ARTEMISS flow diagram

Using these estimates and knowledge of the sensor and surface geometry allows a more precise inversion of the estimated atmospheric transmission using the AMOEBA (also called NelderMead or Simplex algorithm) optimization method. ${ }^{17}$ The AMOEBA routine creates inputs for the MODTRAN files varying up to 20 parameters. Inclusion of more than just three parameters now allows the variation of the atmospheric temperature profile and the addition of sub-visible clouds and cirrus clouds between and above the sensor. The two main advantages are that significantly fewer MODTRAN runs are required and it is possible to simultaneously optimize sensor parameters such as a channel position offset and instrument line spread function, the latter of which is often difficult to characterize. Figure 7 shows how the new version of ARTEMISS works. Note that the AMOEBA step takes approximately as much central processing unit (CPU) time as the generation of a TUD-LUT, but the temperature retrieval based on the continuum interpolated band ratio (CIBR) (Fig. 7) is very fast and the generation of the emissivity cube is based on Eq. 4. 


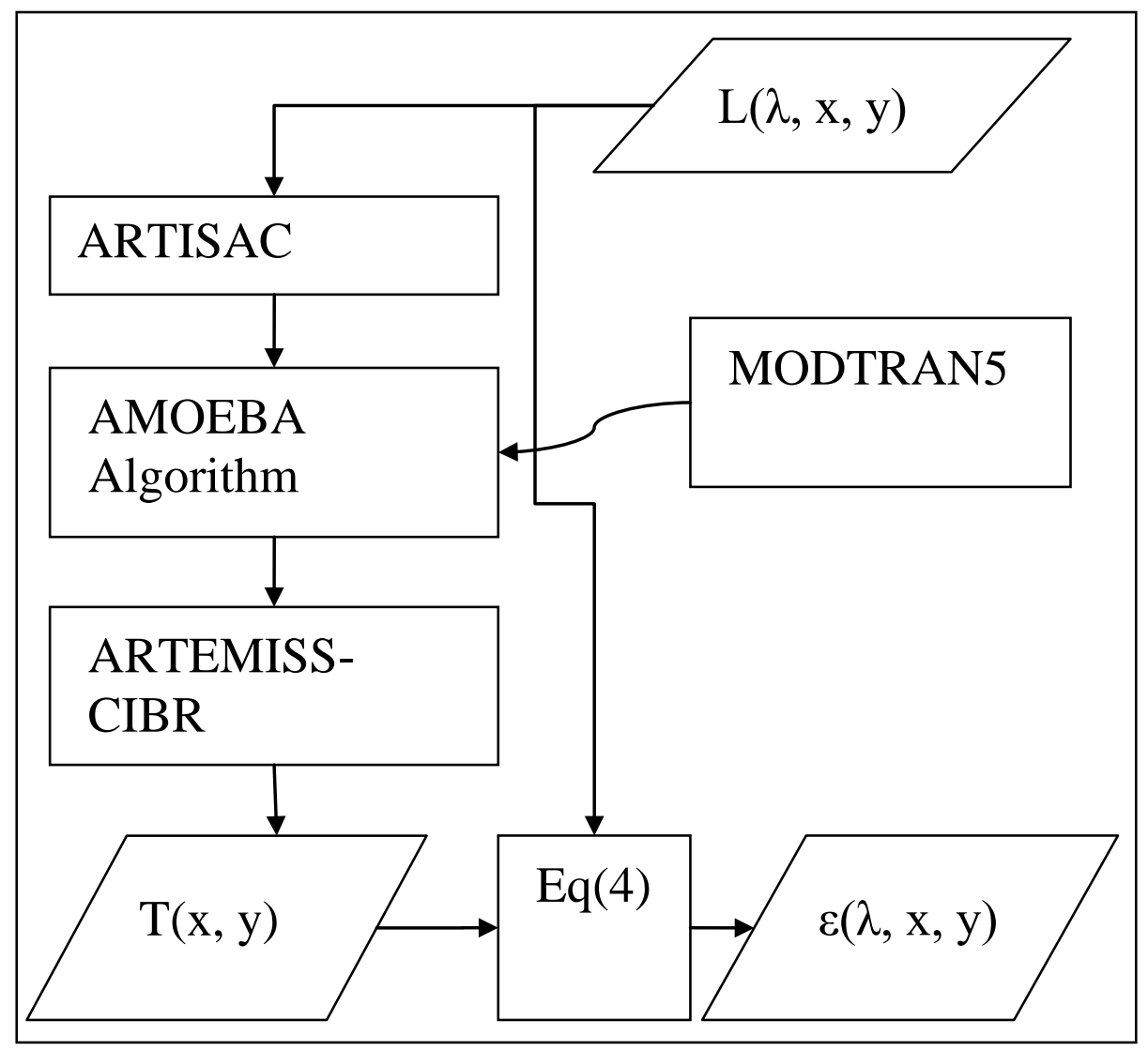

Fig. 7 New ARTEMISS algorithm based on iterative retrieval of the atmosphere based on the AMOEBA algorithm followed by the fast three-band ratio technique (CIBR) to retrieve temperature

The improved ARTEMISS algorithm, as shown in Fig. 7, was used in the estimation of and separation between temperature and emissivity using radiometrically calibrated LWIR hyperspectral imagery in the SPICE dataset.

\subsection{Qualitative Data Assessment}

Under SPICE, the Telops LWIR Hyper-Cam has been employed using the setting for continuous and autonomous data collection for the very first time in this product's history, according to Telops. This setting adds significantly more challenges to a data collection effort, since a human operator is out of the loop and cannot make appropriate sensor parameter adjustments to account for changing conditions in the scene (atmospheric changes, diurnal cycle). So, concerns regarding data quality under this setting are justifiable.

We used SPICE data (July-Sept 2012 collection) to code a standard radiometric calibration method for the SPICE dataset. The raw data preprocessing and calibration methods used in the code have been described previously ${ }^{4}$ (preprocessing) or are outlined in Section 2.4 (calibration). The code has been used at ARL in a mass production setting for the radiometric calibration of SPICE hyperspectral LWIR data. (The data received from ARDEC are raw [Michalson 
interferogram] data of the scene [5-min interval measurements] and two [hot and cold] blackbody objects [hourly measurements from a zero range]). The spectral resolution was set at once to 4 wavenumbers, which produced 164 bands between 8 and 11.5 micron; additional specs are given later.

Figure 8 depicts a typical diagnostic output from the application of the calibration/TES code.

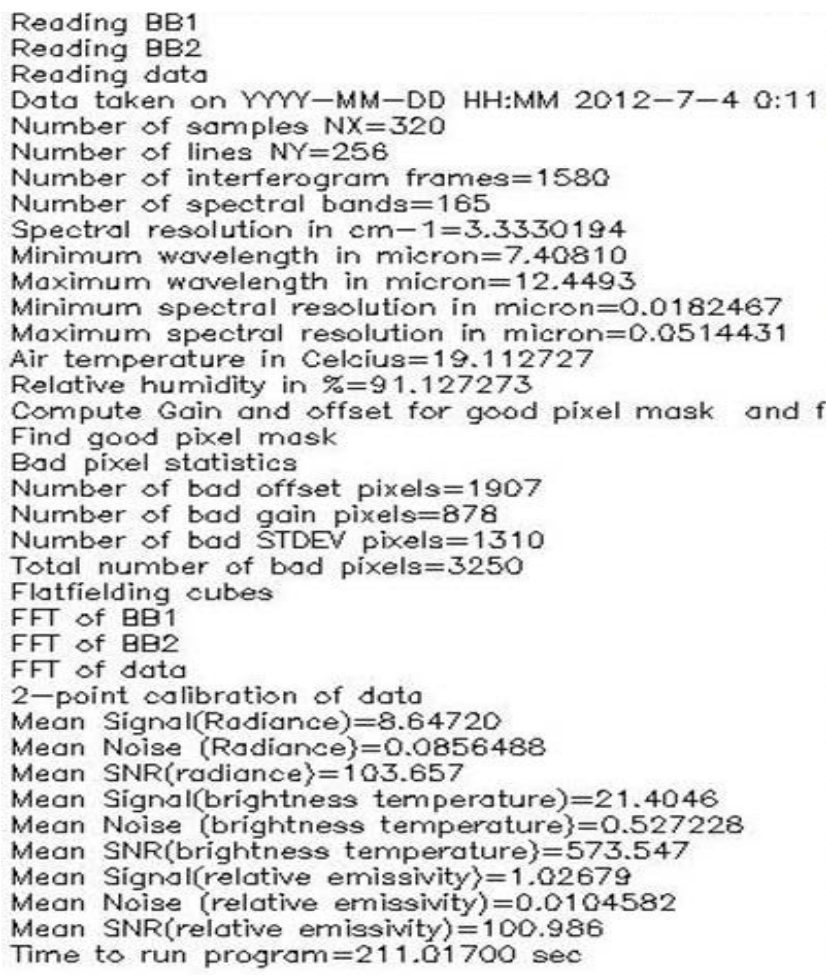

Compute Gain and offset for good pixel mask and flatfielding

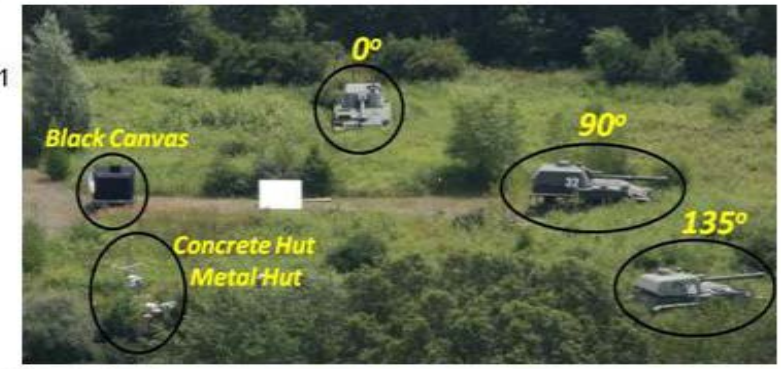

Fig. 8 Typical AFIT calibration/TES code's diagnostic output using SPICE LWIR hyperspectral data

Calibration used measurements from two blackbodies (referred to as BB1 and BB2 in Fig. 8). Figure 8 shows the retrieved temperature image (lower right) of the SPICE test scene (picture upper right); the data were collected July 2012 at $2300 \mathrm{~h}$. The retrieved temperature image shows well-resolved temperature values from spatial observations from the cooler ground toward the top of canopy vegetation (bushes, trees).

Summarized in Section 2.4 is basic information about the corresponding data cube (e.g., cube size, minimum and maximum wavelengths, and spectral resolution), some data quality numbers (e.g., number of bad pixels), and some MET data. The temperature image of the test scene at ARDEC (SPICE data collected around $2300 \mathrm{~h}$ on July 2012) is shown in the lower-right side of Fig. 8; the upper-right side image in Fig. 8 is the red, blue, green (RBG) color picture of the same test site, which includes labeled markers highlighting the manmade objects in the scene. Note that the temperature of a floral bush in the scene could be clearly observed as a smooth, gradually increasing set of values from a location closer to the ground soil (where it was colder) 
to the top of the bush (where it was warmer). Examples of such a temperature resolution within a relatively small spatial area containing the same object would not be possible from a dataset that did not contain an adequate amount of spectral information from the objects in the scene. This reinforces, once again, that the SPICE LWIR hyperspectral dataset is rich in spectral content and temporal variation.

In other examples, not included in this report, we saw favorable results from a temporal analysis performed using another software tool developed at AFIT and tailored to the SPICE data format and available MET data. Some of the plots we saw depicted retrieved temperature values in Celsius, as a function of time, of multiple material types in the test scene estimated using the software tool on the calibrated SPICE LWIR hyperspectral data. Results from canopy tree leaves could be highlighted, since this material type is often used in the scientific community as an approximate representation of a perfect radiation emitter-a blackbody. We point out that the retrieved temperature values of canopy tree leaves, retrieved from radiometrically calibrated SPICE LWIR Hyper-Cam data cubes, showed an almost perfect alignment fit through a 24-h time period with the actual air temperature values that were measured using an independent thermometer at the scene. Accordingly, this is a vote of confidence on the spectral content adequacy of the SPICE LWIR hyperspectral data, because, while temperature is independent of wavelength, the TES method does depend on the spectral content adequacy of the calibrated data and corresponding signal-to-noise ratio (SNR).

To appreciate how much spectral variability one should expect due to various sources of noise imposed on the spectral measurements from a scene, see Figs. 9 through 11. The color code in Figs. 9 through 11 features colored boxes (showing where spectra in the imagery were sampled from to compute average object spectra, e.g., Fig. 9), colors associated with spectral plots (Figs. 9 through 11), and colors associated with object-name fonts (Figs. 9 through 11). The spectral interval for the sensor's operational specs is between 8.0 and 11.5 micron. Figure 9 shows an example of a daytime partly cloudy condition, where the downwelling radiance is a mixture of Planck's blackbody radiance from the clouds and clear sky. Figure 10 (top) shows an example of night and cloudy conditions, where the downwelling radiance matches the environment and both are at the same temperature. Figure 10 (bottom) depicts an example of daytime cloudy conditions, where clouds behave like a Planck's blackbody when the environment is hotter than cloud temperature. Figure 11 (top) shows an example of a thermal cross-over, where the downwelling radiance matches the environment and all surfaces have the same temperature. Figure 11 (bottom) shows an example of a daytime clear and hot condition, where trees show a Planck's blackbody radiance, the surrogate howitzers are hotter than the environment and show absorption features, and the sky plate reflects cold sky. 


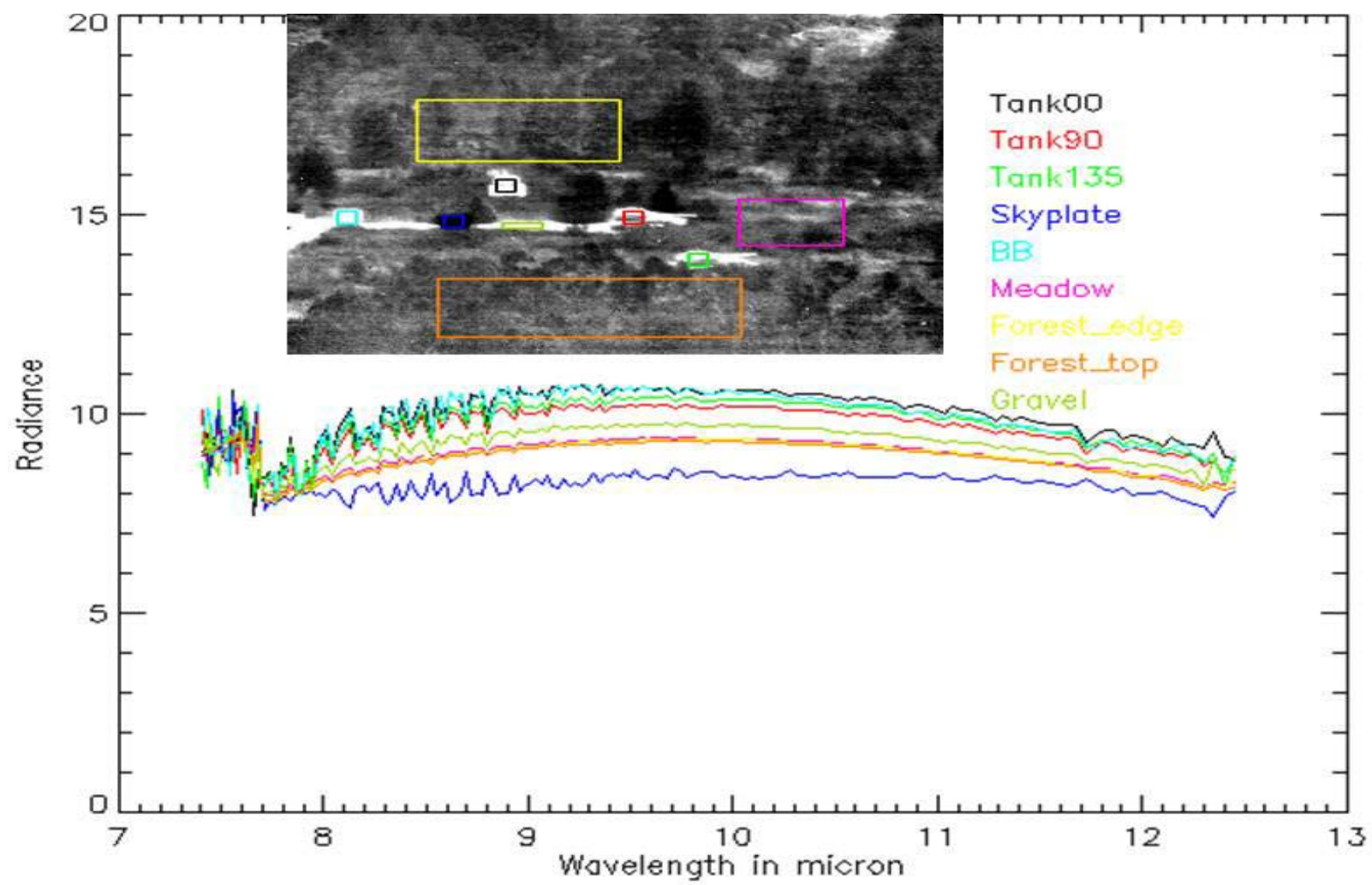

Fig. 9 Example of daytime partly cloudy condition; downwelling radiance is a mixture of Planck's blackbody radiance from the clouds and clear sky. The color code corresponds to color-box-highlighted objects in the scene, plot colors, and colored object-name fonts. The spectral interval of the sensor's operation under specs is between 8.0 and 11.5 micron. 

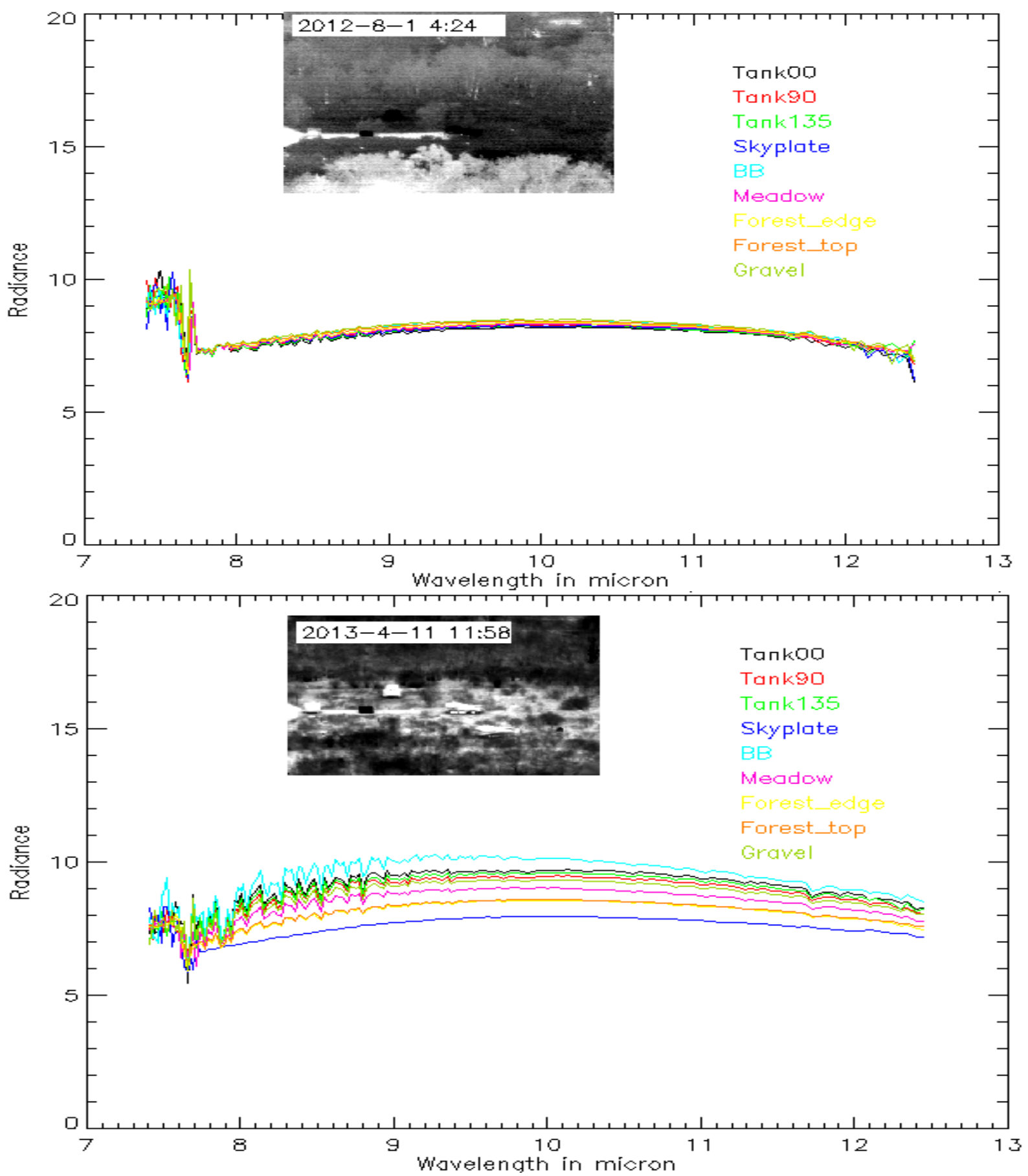

Fig. 10 (Top) Example of night and cloudy conditions; downwelling radiance matches the environment, which is at the same temperature. (Bottom) Example of daytime cloudy conditions; clouds behave like a blackbody when the environment is hotter than cloud temperature. (The color code corresponds to the same one in Fig. 12.) The spectral interval under specs is between 8.0 and 11.5 micron. 

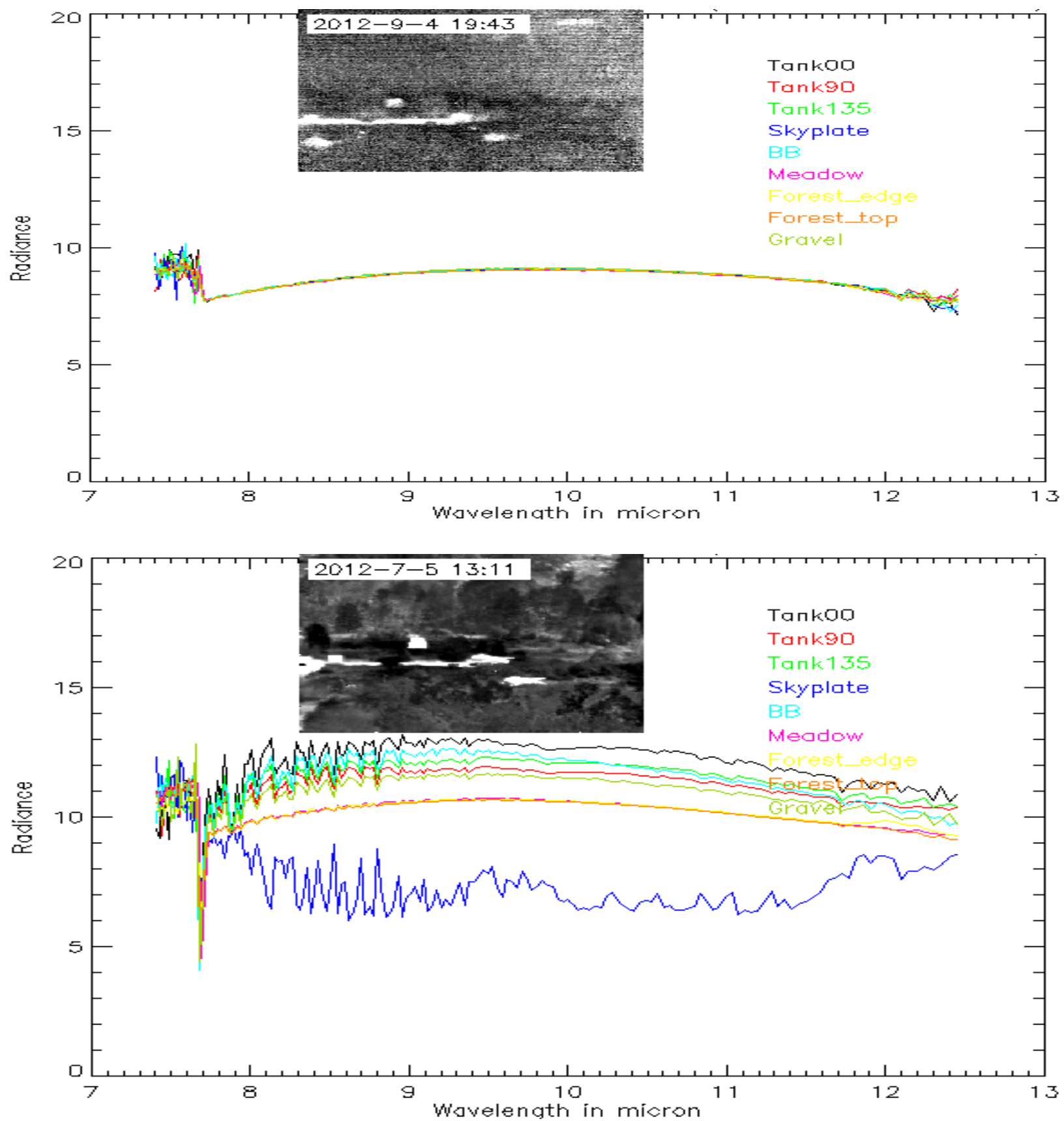

Fig. 11 (Top) Example of a thermal cross-over; downwelling radiance matches the environment and all surfaces have the same temperature. (Bottom) Example of daytime clear and hot conditions; trees show a Planck's blackbody radiance, surrogate tanks are hotter than environment and show absorption features, and sky plate reflects cold sky. (The color code corresponds to the same one in Fig. 9.) The spectral interval under specs is between 8.0 and 11.5 micron.

Our general assessment of calibrated SPICE data is that, while the dataset is noisier than some other datasets collected with far more expensive sensors, the dataset is rich in spectral content and temporal variation, forming a unique set that will be of significant value to researchers. 
We also performed occasional sanity checks on samples of calibrated SPICE LWIR hyperspectral data cubes. As a first cut, understanding that various factors can contribute to the apparent radiance observed in material spectral profiles (e.g., surface-reflected downwelling sky radiance, atmosphere path radiance, downwelling cloud radiance, downwelling radiance from the environment, degraded sensor SNR due to unstable temperature levels [between the sensor and local air temperature, caused, for instance, by relatively high winds in the tower facility]), we focused on two basic aspects, checking for the following:

1. Spectral distinction among spectra of different material types, independently of the atmospheric absorption features observed in individual spectrum, and

2. Consistency (appearance-wise) of spectral profiles from objects spatially apart in the scene, but having the same material (e.g., same paint [surrogate howitzers]).

A simple and fast way to address these aspects, while reducing the ripple in spectra, is to average spectra representing a single object in the scene and visually compare the resulting sample average mean spectra to different objects in the scene. Figure 12 depicts results using this approach.
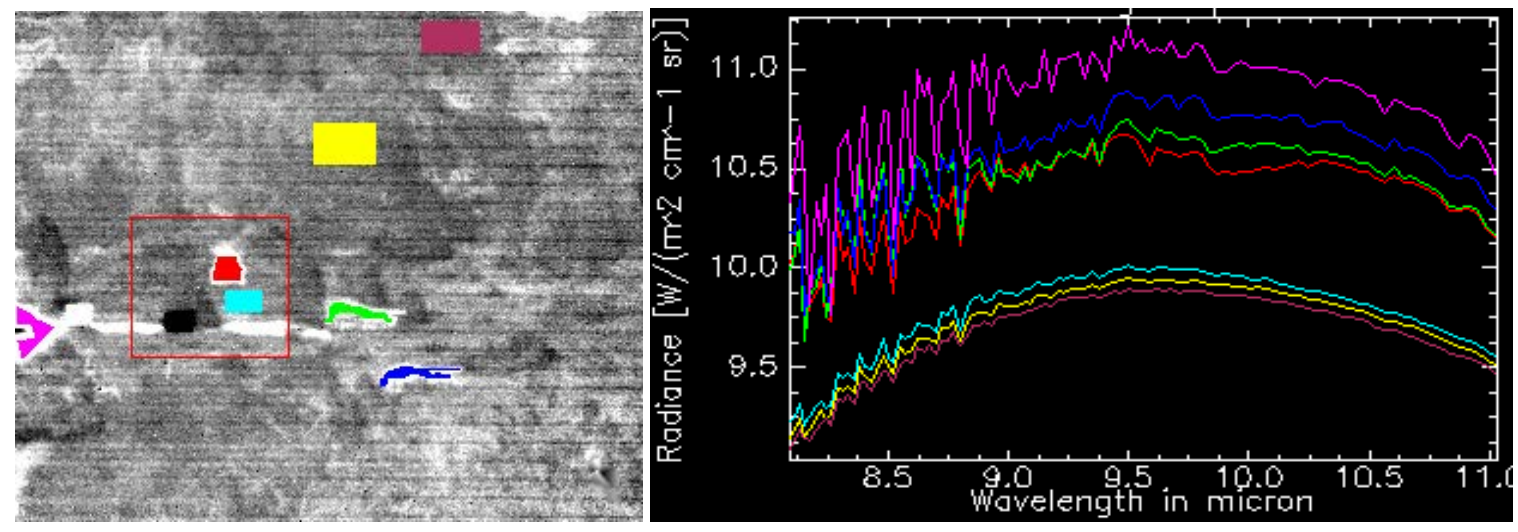

Fig. 12 (Left) Single band image (of the same scene shown in Fig. 8) depicting data blocks used to estimate the average mean spectra of spatially apart objects in the scene; some of these objects have the same material type. Surrogate targets: red region $\left(0^{\circ}\right.$ aspect angle), green area (same paint/tank posed at $\left.90^{\circ}\right)$, and dark blue area (same paint/tank posed at $135^{\circ}$ ). Vegetation trees: yellow and dark magenta (upper right) area. Sparse grass and soil: light blue area. Dirt/pebble road: magenta area (far left middle). (Right) Sample average spectral profiles representing selected spatial areas in the scene shown in the left-hand side image; spectra within each color area were the only ones used to produce the average spectral profile per color area. The plot color code corresponds to the same one in the left image.

In Fig. 12 (right), the spectral sample average plots of three surrogate howitzers (dark blue, green, and red) show a reasonable level of similarity (appearance-wise) across the wavelengths, despite of the fact that the three objects are spatially apart from each other and posed at distinct aspect angles $\left(0^{\circ}, 90^{\circ}\right.$, and $135^{\circ}$; these targets are also denoted herein as $\mathrm{T} 0$, T90, and $\mathrm{T} 135$, respectively). Natural canopy material also shows similar favorable results, as seen in the spectral profiles from grass (light blue) and vegetation trees (yellow and dark magenta). These 
results address the concern in the first aspect mentioned previously and give another vote of confidence on the suitability of SPICE data for algorithmic R\&D. (These favorable results were also observed using a number of other arbitrarily chosen SPICE data cubes.) It is worth noting that the general spectral characteristics of the tanks shown in Fig. 12 will likely not be duplicated in a scenario where the same target is spectrally measured from a zero or near zero range (e.g., $1.5 \mathrm{ft}$ ), for reasons discussed shortly.

Another vote of confidence in the SPICE data are the spectral similarities found in sample data of the same scene while recorded by the two independent Hyper-Cams (AFIT vs. ARL). Fortunately, the AFIT-owned Hyper-Cam was also used in a very limited basis to collect data of the same target site at ARDEC - a year earlier (July 2011) than the starting date of the SPICE data collection (July 2012). In particular, the AFIT sensor recorded a small number of data cubes during daytime only in July 2011. Figure 13 illustrates spectral profiles among different material types in imagery independently acquired a year apart by both Hyper-Cams. It is readily noticeable from Fig. 13 that the spectral profiles (a spectrum per material type) are comparable between both data cubes.

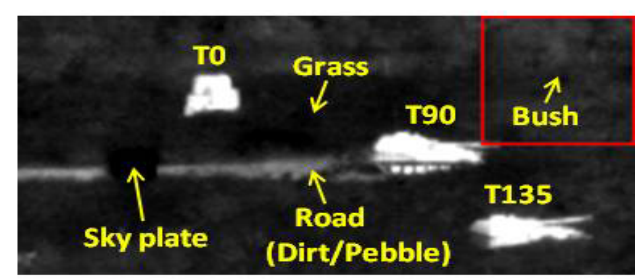

AFIT HyperCam: band 9.5 micron July 2011, 1630h

AFIT HyperCam: 206 bands

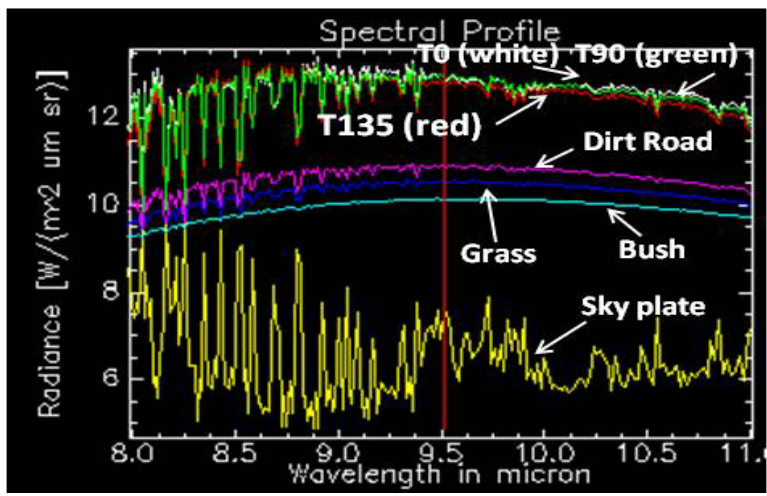

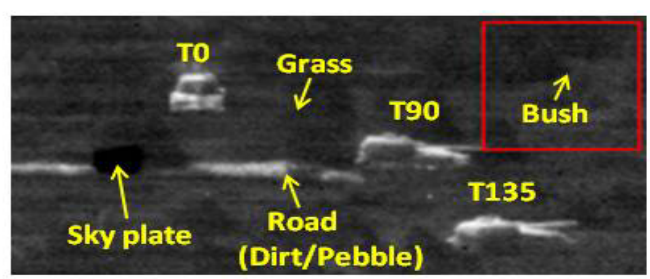

ARL HyperCam: band 9.5 micron July 2012, 1830h

ARL HyperCam: 103 bands

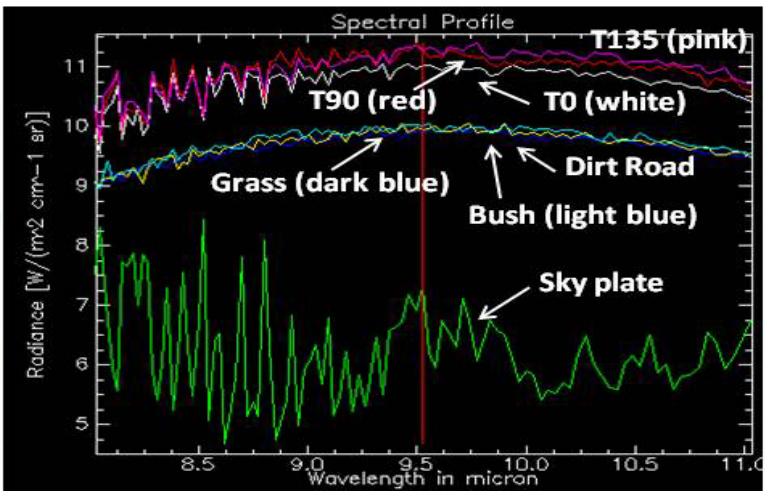

Fig. 13 Illustration of spectral profiles of different material types at the ARDEC SPICE site, where (left) data from the AFIT-owned Hyper-Cam were collected in July 2011 and (right) data from the ARL-owned Hyper-Cam were collected a year later in July 2012

The AFIT sensor acquired data on a particular day in July 2011 using a spectral resolution of 2 wavenumbers, or 324 center bands between 7.41 and $12.32 \mu \mathrm{m}$, and had a human operator monitoring the collection of each individual data cube acquisition at a time, changing sensor parameters when appropriate to maximize data quality (e.g., integration time, optical focus). To 
improve the SNR, 31 data cubes were averaged in the sensor's electronic card to produce a final data cube version representing a single acquisition; this number is the maximum allowed by the Hyper-Cam, significantly increasing the time required for a single data cube acquisition.

The ARL sensor acquired data on most days in July 2012 (a year later from the AFIT data acquisition), using a spectral resolution of 4 wavenumbers, or 165 center bands between 7.41 and $12.45 \mu \mathrm{m}$. The data acquisition was fully autonomous, having all sensor parameters set to fixed values independently of the time of the day, weather condition, heat index, etc. The ARL sensor internally averaged 16 data cubes to yield an output data cube, compared to AFIT's 31 averaging setting, to improve the SNR.

Fig. 13 depicts a single band image produced by each sensor (top images) and a collection of spectra (single spectrum per material type, no averages from multiple sample spectra) from the ARDEC test site. They represent two general classes of material types: manmade objects, which included three surrogate howitzers posed at three aspect angles (counterclockwise) $135^{\circ}$ (T135), $90^{\circ}(\mathrm{T} 90)$, and $0^{\circ}(\mathrm{T} 0)$, and natural objects (vegetation bush, grass, and dirt road). Notice in Fig. 13 (bottom plots) that between 8.0 and $11.0 \mu \mathrm{m}$, the manufacturer's specified range of operation for both Hyper-Cams, the AFIT sensor produced twice the number of bands as compared to the ARL sensor (206 versus 103). A key point from these spectral plots is the strong visual similarity between spectral samples of the same material type independently produced by each sensor a year apart. For instance, the apparent radiance at the sensor from the sky plate (aluminum plate) in the scene is dominated by the surface-reflected downwelling sky radiance toward the sensor. Notice also that the most dramatic spectral features in the sky plate spectral profile can be equally observed in corresponding sky plate spectrum recorded by each sensor. These features are not observed in spectra of other material types, although the high oscillation between 8.0 and $9.3 \mu \mathrm{m}$ due to water vapor and other gases is also observable in corresponding spectra of three other manmade objects in the scene (T0, T90, and T135), as these strong spectral featured are added during transmission of radiance from these objects through the atmosphere toward the sensor (path radiance), in addition to surface-reflected downwelling radiance from other nearby objects in the scene.

The spectral characteristics of the surface-reflected downwelling sky radiance shown in Fig. 13 for both sensors are consistent with the downwelling sky radiance models discussed in the literature. Figure 14 shows that spectral features from ozone gas in the atmosphere between 9 and $10 \mu \mathrm{m}$ are also observed. ${ }^{3}$ 


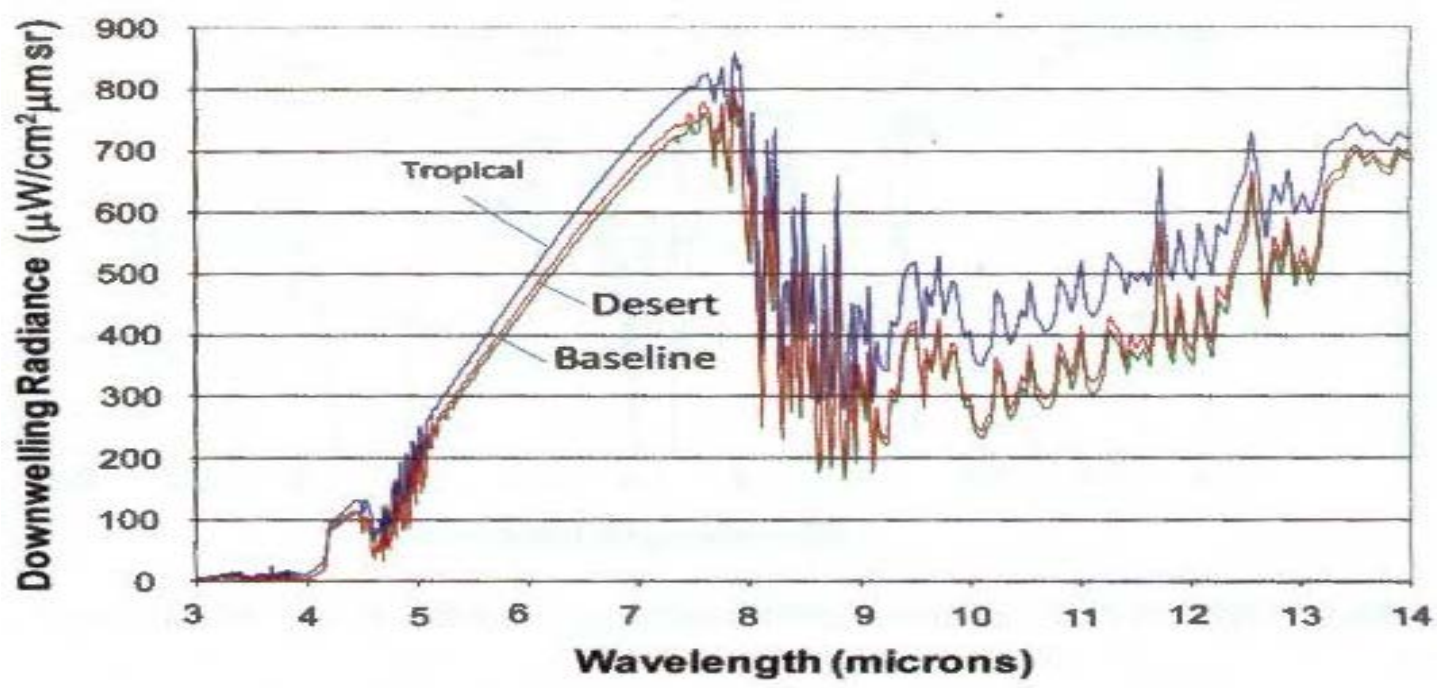

Fig. 14 MODTRAN models: MWIR/LWIR diffuse downwelling radiance as a function of atmospheric conditions

Notice in Fig. 14 that there is a measureable amplitude difference (not a spectral shape difference) between downwelling sky radiance propagating in a tropical-like atmosphere, where air humidity is relatively high, as compared to a desert or some other condition. This is notable since the portion of the LWIR region of the spectrum that is relevant to the Telops' Hyper-Cam is between 8 and 11 microns, Fig. 12 shows the applicable interval from plots in Fig. 14 coarsely aligned with ARL sensor's measurement of downwelling sky radiance shown earlier in Fig. 13; the correspondence among the various spectral characteristics between the MODTRAN models and ARL measurement is self-evident, where the atmospheric condition in July 2012 at the ARDEC test site is closer to the tropical condition portrayed in the model's spectral plot. (MODTRAN is a computer program designed to model atmospheric propagation of electromagnetic radiation for the 0.2 to 100 micron spectral range. ${ }^{6}$ )

The message to be emphasized from Fig. 14 is the presence of a clearly observable strong correspondence among the downwelling sky radiance plots from the MODTRAN models, the sample AFIT Hyper-Cam measurement, and the sample ARL Hyper-Cam measurement, which also gives a strong indication of the sky atmospheric condition during collection of the specific SPICE LWIR hyperspectral downwelling sky sample spectrum presented in Fig. 13, i.e., clear horizon with partial stratus clouds.

Over the years, analysis between MODTRAN models and Telops' Hyper-Cam measurements of downwelling sky radiance has been a topic of discussion in technical conferences and workshop; a Google search with the appropriate keywords would find some of these materials. It is beyond the scope of this report to discuss this topic further; however, to show an indication of this type of work, we provide Fig. 15 as an example of a similar analysis performed using the AFIT Hyper-Cam. Additional challenges are shown in Fig. 16. 


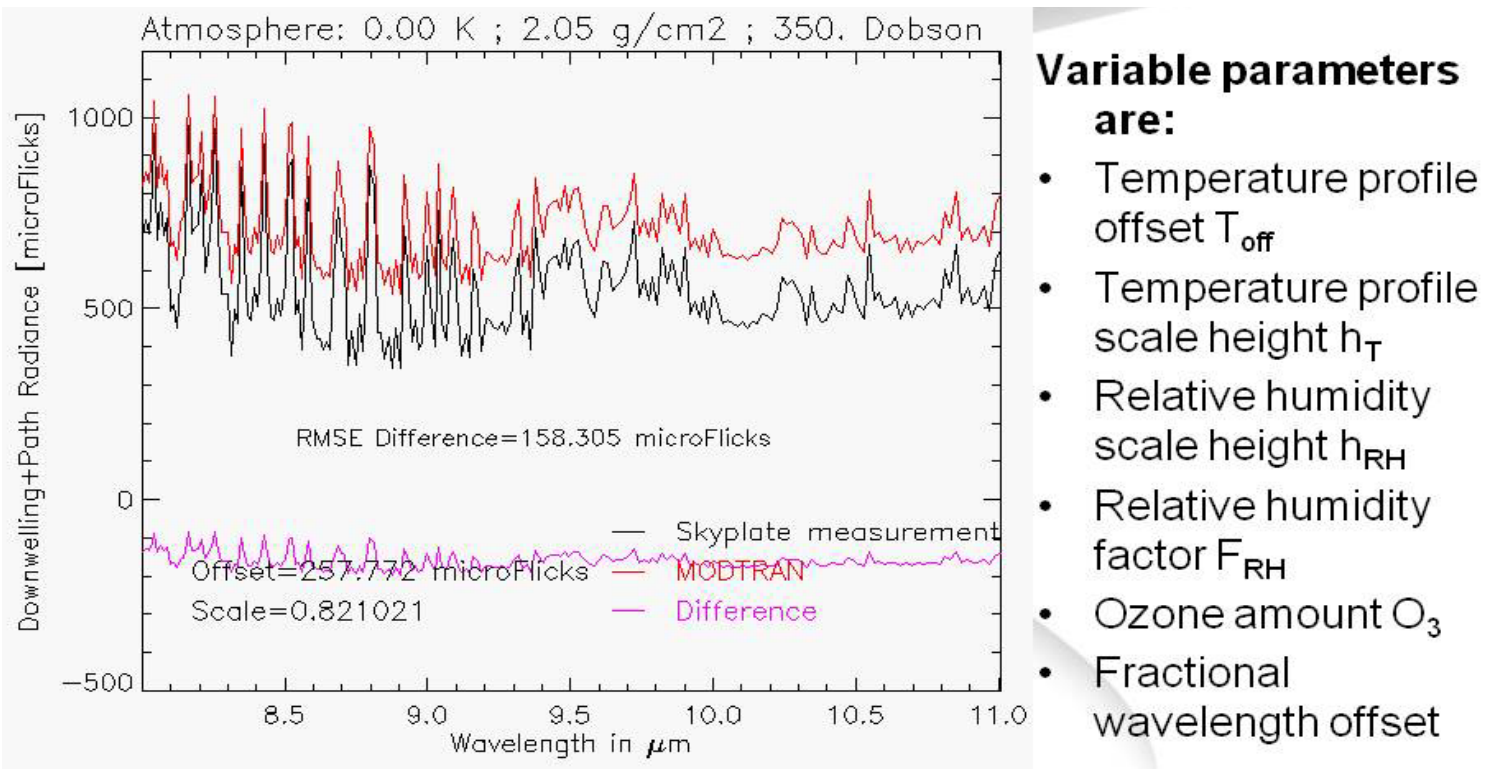

Fig. 15 MODTRAN vs. real measurements of the downwelling sky radiance analysis using the AFIT-owned Hyper-Cam, where such a validation was needed for the development of the QTES code 

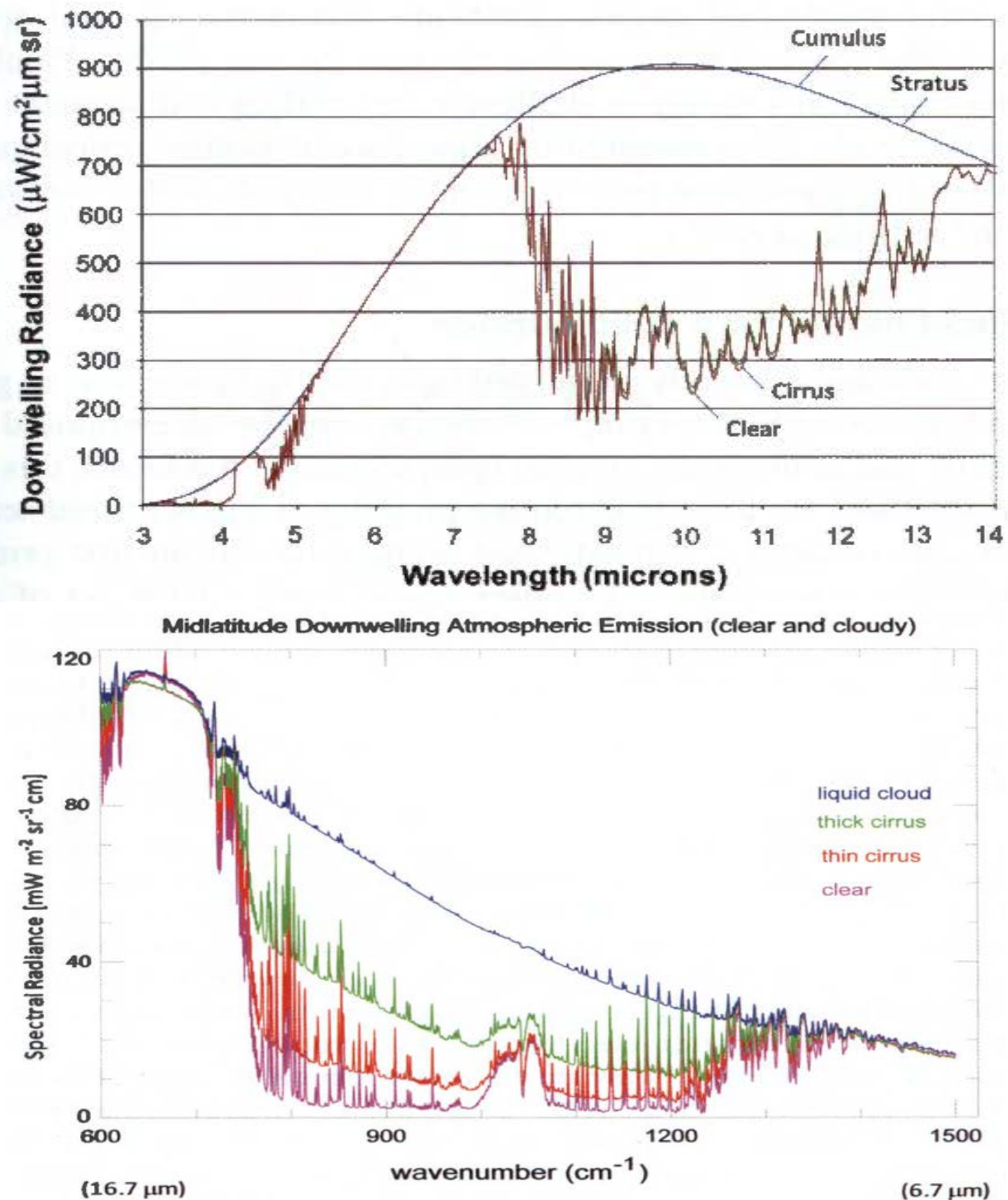

Fig. 16 (Top) MWIR/LWIR diffuse downwelling radiance as a function of cloud conditions. (Bottom) LWIR downwelling radiance measurements for different cirrus cloud thicknesses compared to clear sky and liquid clouds.

As would be expected, changes in the atmosphere (e.g., presence and thickness of specific types of clouds) and data collection parameters (e.g., sensor viewing perspective) can cause some significant variation in remotely measured spectra; see the spectral profiles in Fig. 13 for examples of some of these changes. 
As mentioned, Fig. 16 shows the MWIR/LWIR diffuse downwelling radiance as a function of cloud conditions: clear, cumulus (below 6,000 ft), stratus (below 6,000 ft), and cirrus (above $18,000 \mathrm{ft}$ ). The thickness of these clouds will determine whether their downwelling radiance will behave like the one shown in Fig. 16; cloud thickness or liquid level, for instance, explains the difference between the downwelling radiance shown for stratus in other measurements from Fig. 16 (top side). ${ }^{3}$ Figure 16 (bottom side) further depicts the effect of cloud thickness, using as reference cirrus cloud, where radiance is shown as a function of wavenumber $\left(\mathrm{cm}^{-1}\right)$, not wavelength.

The plots in Fig. 16 emphasize additional expected complexity for developing physics-based LWIR radiance models and making correct data quality judgments from real hyperspectral LWIR measurements (e.g., SPICE dataset). These plots also emphasize the inherent difficulties one would have in comparing spectral samples of the same material from real hyperspectral data cubes without having full knowledge of the data collection ground truth (e.g., sensor's viewing perspectives, range, cloud, and wind conditions); some of this information is often not available.

Beyond the downwelling sky radiance, it would also be helpful to take a closer look at the spectral profiles of another manmade object in the scene, using data from both sensors. Figure 17 shows the alignment of a corresponding sub-sampled version of another example manmade material spectrum recorded by the AFIT sensor. In this case, we arbitrarily keep every other radiance value among the 206 bands in order to match the number of bands produced by the same manmade object in the SPICE data (103 bands). Of course, by following this procedure, one would not expect to align the radiance values from the AFIT sensor with the exact 103 center wavelengths produced by the ARL sensor, and vice versa; however, since the only interest here is to observe course trends in the spectra, sub-sampling was employed for visual comparison of the spectra using the center wavelengths of the ARL sensor for the band horizontal axis. Figure 17 shows the resulting spectral profiles of target $\mathrm{T} 0$ as the example manmade object. 

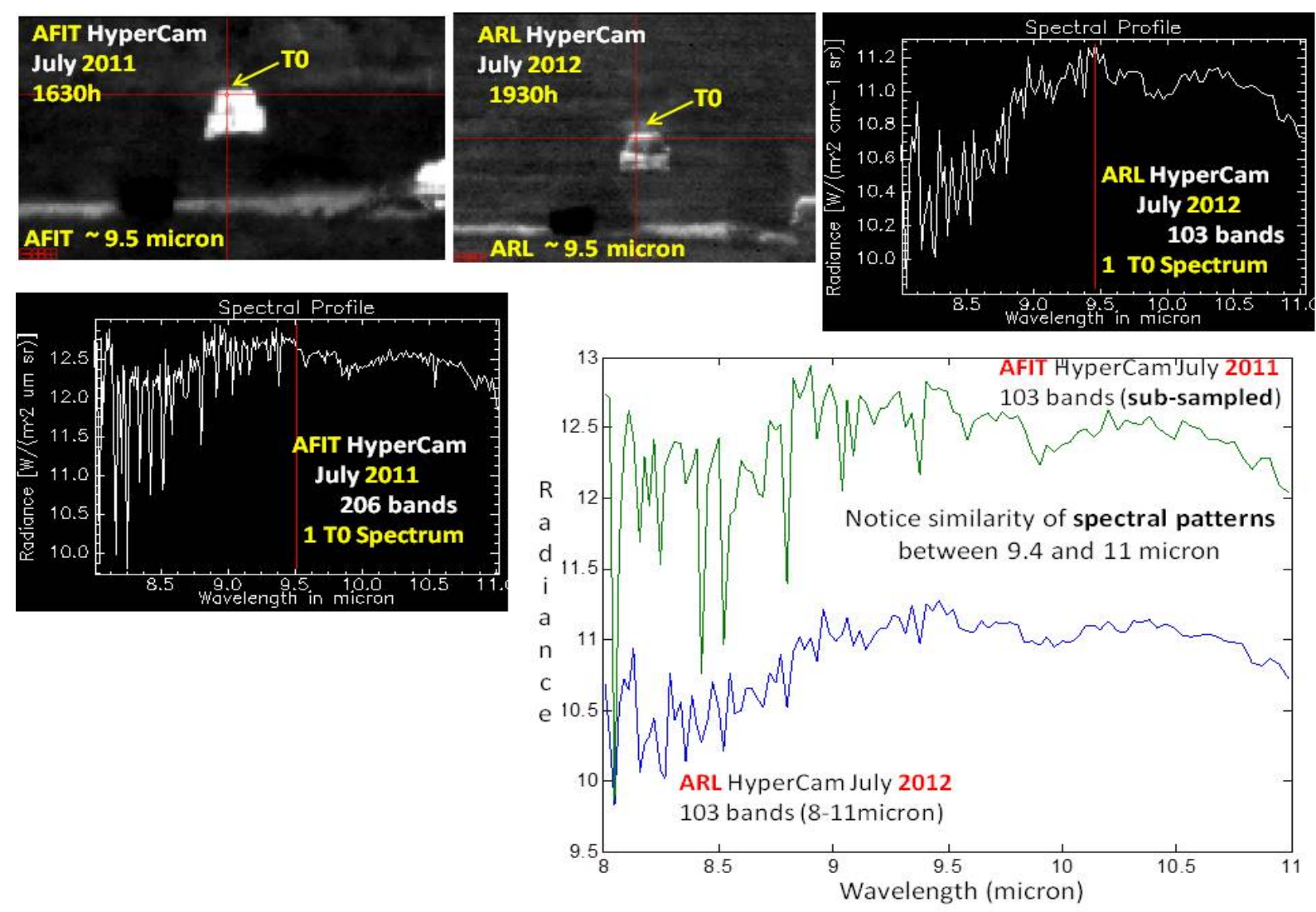

Fig. 17 Spectra from the same object (target T0) and approximate pixel location on the target, both collected by two independent Hyper-Cams (AFIT vs. ARL) a year apart (July 2011 and July 2012). The strong oscillation patterns between 8.0 and $9.4 \mu \mathrm{m}$ are due to water vapor concentration in the atmosphere between the target surface and the sensor. Oscillation amplitude is also impacted by the humidity level in the atmosphere. The target (surrogate howitzer) was hotter during AFIT data acquisition and spectral absorptions appear stronger because of its finer spectral resolution than ARL's data. Distinct spectral patterns in both spectra are clearly visible between 9.4 and $11.0 \mu \mathrm{m}$ using both sensors a year apart are encouraging. (The spectrum from the AFIT sensor was sub-sampled from 206 to 103 bands - the number of bands recorded by the ARL sensor, as described in text, so both spectra could be plotted in the same graph.)

Given that both sensors collected data of the same scene but a year apart, Fig. 17 shows a strong match of the target T0's spectral patterns between 9.4 and $11.0 \mu \mathrm{m}$ in both data cubes (AFIT and SPICE). It also shows a direct correlation to the spectral sample averages shown earlier in Fig. 12, representing the three surrogates (T0, T90, and T135). These visual matches give another vote of confidence in the SPICE data, since the exact atmospheric condition is virtually impossible to duplicate between days of the same month a year apart. There are also other uncertainties to be considered, e.g., unknown exact spatial location on the target where the spectra were sampled. The strong oscillation patterns between 8.0 and $9.4 \mu \mathrm{m}$ are likely due to water vapor concentration in the atmosphere between the target surface and the sensor. The amplitude of the oscillation is also impacted by the humidity level in the atmosphere. Let us now address "zero" range data, using the ARL Hyper-Cam (Fig. 18). 

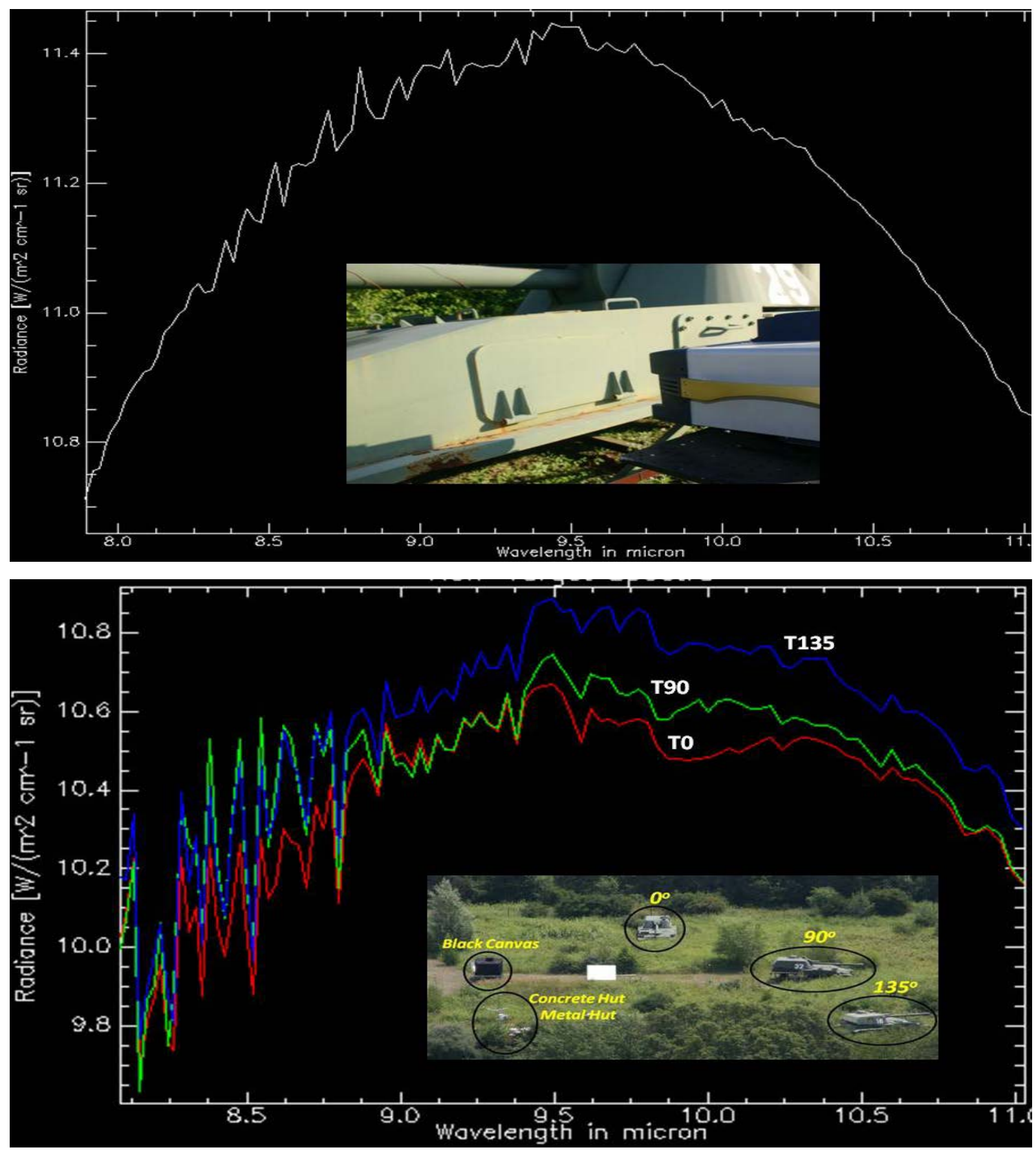

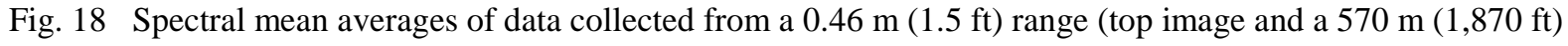
range (bottom image), using the SPICE LWIR Hyper-Cam to collect data of the same material (green paint on the surrogate howitzer target). Due to many factors, spectral differences are expected to exist, given the large difference in range, to include reflection of emitted downwelling sky radiance off the target at far ranges (which is blocked by the sensor's physical presence at close range), and a significantly higher concentration of atmosphere between target and sensors.

As discussed earlier, due to the path radiance, spectral patterns emitted from a particular material surface located at a far range from the sensor, e.g., $0.57 \mathrm{~km}$, will likely differ from spectral 
patterns of the same material type being recorded, instead, by the same sensor at a close range from the target, say less than a meter. To show this distinction, a similar copy of the surrogate howitzer (used to obtain results shown in Fig. 12) was used as the target at a close range, such that, the target's dominant green paint became the specific material of interest. The data were collected in July 2013 around 8:00 am from a 1.5-ft range, using a spectral resolution of 4 wavenumbers (103 bands between 8.0 and 11.0 micron).

The spectral profile shown in Fig. 18 (top: target range $0.46 \mathrm{~m}$ [1.7 ft]) is the spectral mean average using a 10x10 window over the imaged target (target's actual left-hand side). Figure 18 (bottom: target range $570 \mathrm{~m}[18,70 \mathrm{ft}]$ ) shows the same spectral mean averages corresponding to T0, T90, and T135 shown earlier in Fig. 12, where data were collected a year earlier in July 2012 on a different day and time from the close range collect. Notice that the solar load incidence angle on the normal surface of the target painted plate can be appreciated from the center image in Fig. 18 (top), as well as the presence of a tilted shadow (lower left-hand side of center image in Fig.18 [top]) due to the spatial geometry between the sensor and the sun, which was rising on the horizon from the back viewing perspective (right-hand side) of the sensor.

Spectral profile differences are clearly noticeable between Fig. 18 (top) and Fig. 18 (bottom). The spectral differences are attributed to multiple factors, including blocked sky radiance and/or blocked environment radiance by the sensor from reaching the target at close range; pixel spatial resolution differences (e.g., from collects at long ranges a pixel may consist of a mixture of different material types and radiance from multiple surface normal angles relative to collects at close ranges, in which a pixel-vector consists of a radiance vector from a single material surface angle); and the presence of a more concentrated atmospheric effect between the sensor and target-most dominant at longer ranges.

Using an individual spectrum per material type to quantify or qualify spectral differences is not a favorable approach in the scientific community. Because, in addition to the various noise sources already discussed (system noise, atmospheric and environment variation) that will change the spectral profile of a material type, the natural statistical variation of the multivariate distribution function controlling the observed samples of material emitted radiance also does play a role in changing spectral profiles. Figure 19 shows examples of individual spectrum from target T0 recorded by both LWIR Hyper-Cams (ARL and AFIT) at the range of $570 \mathrm{~m}$ (see Fig. 16) and a spectrum from approximately the center spatial location of the data cube measured from the target paint at the range of $0.46 \mathrm{~m}$ (see Fig. 18 [top]). 


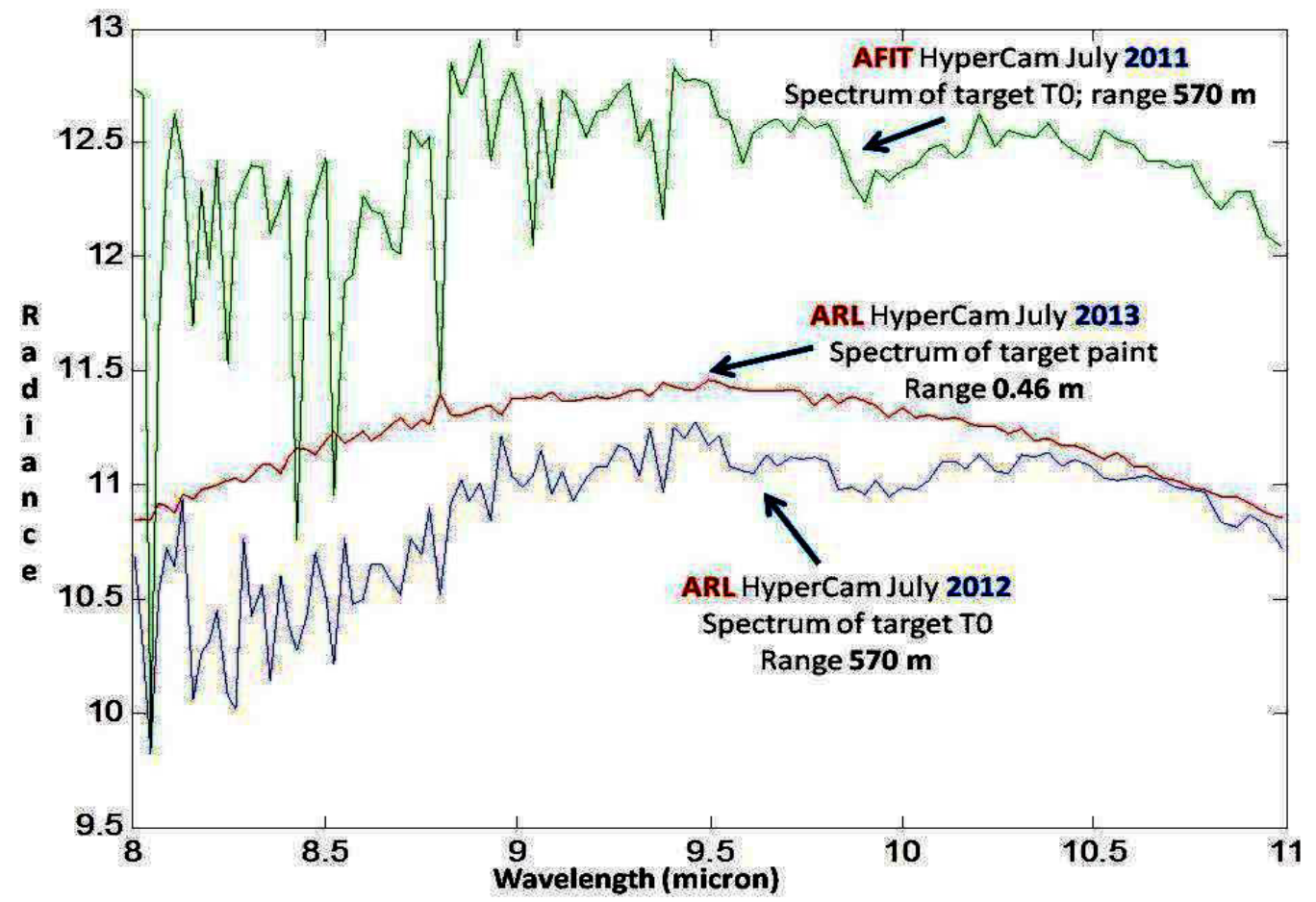

Fig. 19 Examples of individual spectrum of the same target recorded in three different years: July 2011 (AFIT sensor), July 2012 (ARL sensor), and July 2013 (ARL sensor) from two ranges (0.46 and $570 \mathrm{~m}$ ). Among other factors, the cumulative concentration of water vapor in the atmosphere, which increases as a function of range, plays a major role in changing the spectral profile of the target.

A key message from Figs. 18 and 19 is that the reliability of spectral patterns emitted by the same material is not only directly dependent on the atmospheric/cloud conditions, environment (nearby objects in the scene), and system noise, but also equally on range.

Finally, Fig. 20 illustrates the average band images of the same target site during two complete diurnal cycles on 22 July 2012 and 23 July 2012, where a selected number of those images are depicted. 


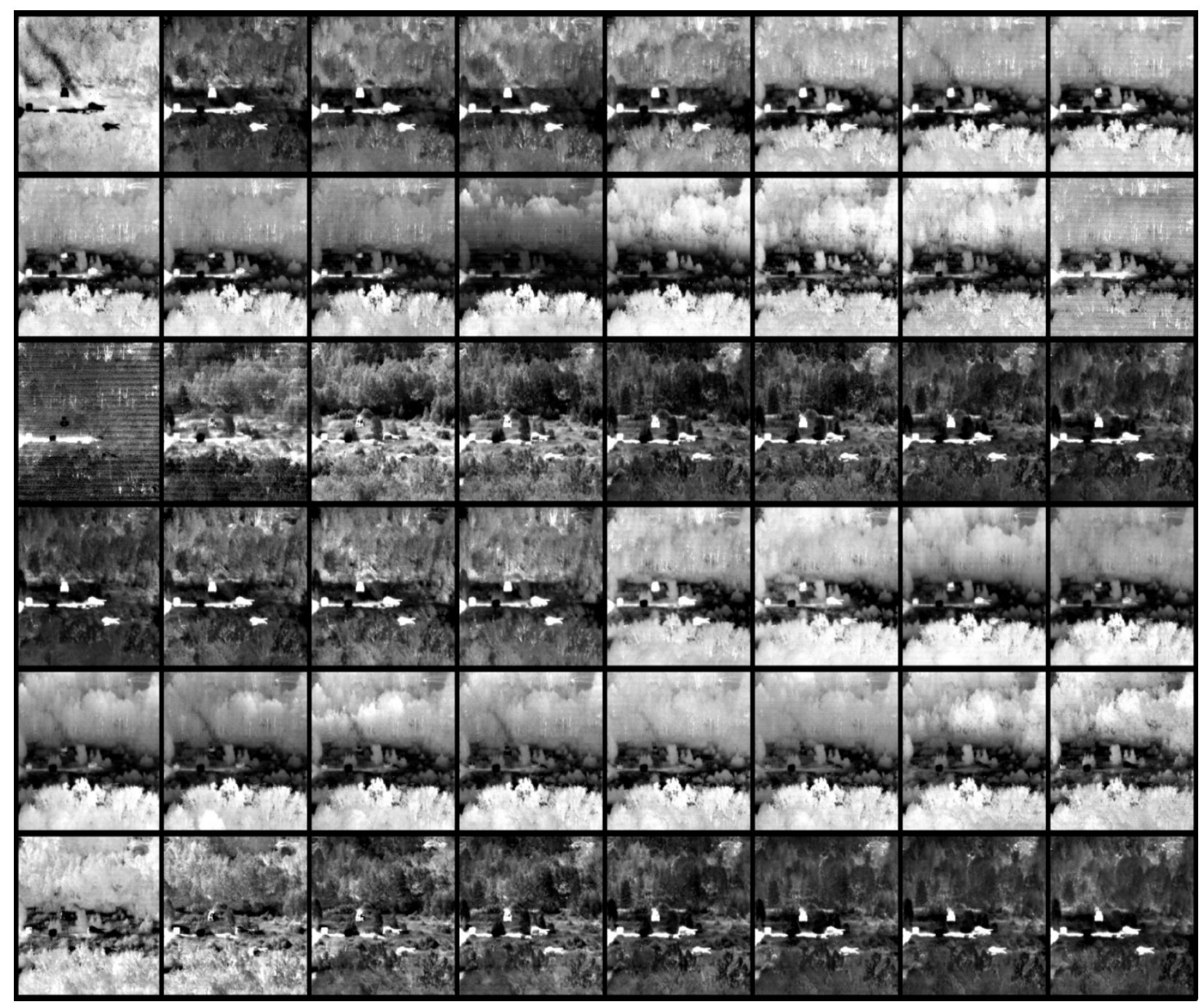

Fig. 20 Selected number of band-averaged images of the same target site during two complete diurnal cycles on 22-23 July 2012

The thermal variability shown in Fig. 20 for each object in the scene suggests that assuming a fixed probability density function (PDF) to model LWIR hyperspectral data is inadequate. Therefore, the results produced by any theoretical method based on this assumption intended to perform anomaly detection, target detection, band reduction, material un-mixing, etc., should be ignored, as they are being applied in an ad-hoc fashion. Incidentally, this assumption covers the bulk of proposed methods in the literature. 


\section{Conclusions}

Investments into LWIR experiments, such as the SPICE dataset that ARL and ARDEC have produced, are very important for the remote sensing community_both military and civilian. The effort will, for the first time, make data available to a wider community and across agencies for full diurnal cycles taken under non-ideal conditions. The dataset is especially valuable because the necessary ground truth, such as weather conditions and calibration targets imaged at the same time as the device under test, is made available as well. Since the SPICE data are taken for surrogate targets in a natural scene, the danger of giving away vulnerabilities is held at a minimum. Data from SPICE could also be used widely in the classroom to educate a new generation of researchers.

From our assessment of the LWIR hyperspectral sensor used in SPICE, we concluded the following:

- Indoor data are comparable between the ARL- and AFIT-owned LWIR Hyper-Cams. This is based on the results from the sensor characterization effort, under a controlled indoor environment at the AFIT Remote Sensing Laboratory. The tests were held during an entire month (see Fig. 2).

- Outdoor (SPICE site) data are comparable between the ARL-and AFIT-owned HyperCams. The AFIT-owned Hyper-Cam recorded a very limited dataset of the same site used for SPICE. The small LWIR hyperspectral dataset was recorded during daytime only in July 2011; SPICE started in July 2012. Figures 13 and 16 depict typical spectral profiles among different material types in imagery independently acquired a year apart by both Hyper-Cams. Visual inspection of these plots reassures that the spectral profiles (a spectrum per material type) are comparable between both data cubes. Similar results were obtained among other data cubes recorded by both sensors. The AFIT-sensor recorded data have twice the spectral resolution of SPICE data between 8 and 11 micron (206 and 103 bands, respectively). It is worth noting that, under SPICE, the Hyper-Cam used a setting of continuous and autonomous data collection for the very first time in this product's history, according to its manufacturer Telops. This setting adds significantly more challenges to a data collection effort, since a human operator was out of the loop and unable to make appropriate sensor parameter adjustments to allow for changing conditions in the scene (atmospheric, diurnal cycle). The data recorded by the AFIT Hyper-Cam (see Fig. 13 [left]) had a human operator in the loop.

- MODTRAN models match the downwelling sky radiance in the SPICE dataset. Providing further reassurance in the SPICE dataset, spectral samples of the aluminum plate deployed at the SPICE site clearly show the surface-reflected downwelling sky radiance 
corresponding to downwelling in the sky models featured in MODTRAN, a computer program designed to model atmospheric propagation of electromagnetic radiation for the 0.2 to 100 micron spectral range. Some of these spectral feature correspondences include 1) the strong spectral oscillation between 8.0 and 9.2 micron due-by a general consensus in the scientific community - to water vapor in the atmosphere and some system noise; and 2) other known infrared absorption lines (e.g., at 11.7 micron also due to water vapor ${ }^{3}$ ) and between 9 and 10 micron (due to ozone molecules ${ }^{4}$ ). Multiple organizations have performed validation studies between MODTRAN5 atmospheric models and actual measurements using the Telops LWIR Hyper-Cam, to include AFIT (see Fig. 15).

Specific to the ARL-owned Hyper-Cam, the sky plate spectral profile shown in Fig. 13 (lower right) corresponds well to the MODTRAN5 downwelling radiance models for the tropical environment as a function of atmospheric condition, as shown in Fig. 14.

The results reinforce the challenges associated with remote sensing data modeling using outdoor hyperspectral LWIR measurements of a specific material, or using spectral samples from such a dataset to populate a library for pattern recognition tasks, as evidenced in Fig. 15 (MODTRAN models of downwelling sky radiance as a function of cloud conditions), and Figs. 9 through 11 (selected examples under conditions of daytime and nighttime, cross-over, hot and clear, partially and full-cover cloudy, etc.). Additional spectral changes in a target's material signature due to range differences are shown in Fig. 17 (close [0.45 m] and far [570 m] ranges using the ARL Hyper-Cam). The spectral changes shown in those figures are far from being exhaustive; they only scrape the surface of atmospheric variation, as adverse weather, for instance, was not included. The key message from those figures is that atmospheric variation can significantly change the expected pure spectral radiance of a material, being remotely observed by a LWIR hyperspectral sensor, since the apparent material radiance at the sensor is the sum of the upwelling material spectral radiance (given the material temperature at the time of data acquisition), the atmospheric path radiance between the material and sensor, the surfacereflected downwelling sky radiance, and the surface-reflected downwelling radiance of nearby objects in the surrounding environment, not to mention changes associated with surface orientation of target material.

The key message in here is that intrinsic system noise in Telops Hyper-Cam recorded data seems to be a minor to moderate concern compared to the effects imposed by atmospheric and environment variation, the latter being responsible for the real challenges behind modeling tasks or lack of algorithm robustness in target recognition applications. 


\section{Future Plans}

The thermal variability depicted in Fig. 20 for each object in the scene suggests that modeling LWIR hyperspectral data with a fixed PDF (hence, fixed parameters) — an assumption widely adopted in the scientific community —is not only inadequate, but incorrect for the development of algorithms intended for autonomous anomaly detection, target detection, band reduction, material un-mixing, among others. In future, we will explore other statistical models, those that are inherently flexible allowing distribution parameters (hence, PDFs) to evolve as a function of time, both diurnally and across days within a narrow time interval. 


\section{References}

1. Romano J, Rosario D, McCarthy J. Day/night polarimetric anomaly detection using SPICE imagery. IEEE Trans. on Geoscience \& Remote Sensing. 2012;50(12):5014-5023.

2. Romano J, Rosario D, Niver E. morphological operators for polarimetric anomaly detection. IEEE Journal of Selected Topics in Applied Earth Observations \& Remote Sensing. 2014;7(2):664-677.

3. Eismann M. Hyperspectral remote sensing. SPIE Press. 2012.

4. Borel C, Rosario D, Romano J. Range-invariant anomaly detection applied to imaging Fourier transform spectrometry data. Proc. SPIE. 2012;85150J-12.

5. Hackwell JA, Warren DW, Bongiovi RP, Hansel SJ, Hayburst TL, Mabru DJ, Sivjee MG, Skinner JW. LWIR/MWIR imaging hyperspectral sensor for airborne and ground-based remote sensing. Proc. SPIE. 1996;2819.

6. Berk A, Anderson G, Acharya P, Bernstein L, Muratov L, Lee J, Fox M, Adler-Golden S, Chetwynd J, Hoke M, Lockwood R, Gardner J, Cooley T, Borel C, Lewis P, Shettle E. MODTRAN5: 2006 update. Proc. SPIE. 2006;6233.

7. Realmuto VJ. Separating the effects of temperature and emissivity: emissivity spectrum normalization. Proc. of the Second TIMS Workshop. JPL Publ. 1990;90-55:31-35.

8. Kahle AB, Madura DP, Soha JM. Middle infrared multispectral aircraft scanner data: analysis for geologic applications. Applied Optics. 1980;19(14):2279-2290.

9. Hook SJ, Gabell AR, Green AA, Kealy PS. A comparison of techniques for extracting emissivity information from thermal infrared data for geologic studies. Remote Sens. Environ. 1992;42:123-135.

10. Matsunaga T. An emissivity-temperature separation technique based on an empirical relationship between mean and range of spectral emissivity. Proc. 14th Japanese Conf. of Remote Sensing. 1993;47-48.

11. Johnson BR, Young SJ. Inscene atmospheric compensation: application to SEBASS data at the ARM site. Aerospace Report No. ATR-99(8407)-1 Parts I and II, 1998.

12. Young SJ. Detection and quantification of gases in industrial-stack plumes using thermalinfrared hyperspectral imaging. The Aerospace Corporation Report No. ATR-2002(8407)-1, 2002. 
13. Gu D, Gillespie AR, Kahle AB, Palluconi FD. Autonomous atmospheric compensation (AAC) of high resolution hyperspectral rhermal infrared remote-sensing imagery. IEEE TGARS. 2000;38(6):2557-2570.

14. Borel CC. Iterative retrieval of surface emissivity and temperature for a hyperspectral sensor. First JPL Workshop on Remote Sensing of Land Surface Emissivity, May 6-8, 1997. (available only from the author's Web site: http://www.borel.net).

15. Salisbury JW, D'Aria DM. Emissivity of terrestrial materials in the 8-14 $\mu \mathrm{m}$ atmospheric window. Remote Sens. Environ. 1992;42:83-106.

16. Borel C. Error analysis for a temperature and emissivity retrieval algorithm for hyperspectral imaging data. International Journal of Remote Sensing. 2008;2(17-18):5029_ 5045(17).

17. Press WH, Flannery BP, Teukolsky SA, Vetterling T. Numerical recipes in C: the art of scientific computing. Cambridge University Press, Cambridge, 1988.

18. TELOPS homepage http://www.telops.com (accessed 28 September 2011). 


\section{List of Symbols, Abbreviations, and Acronyms}

$\begin{array}{ll}\text { AFIT } & \text { US Air Force Institute of Technology } \\ \text { ARDEC } & \text { US Army Armament Research, Development, and Engineering Center } \\ \text { ARL } & \text { US Army Research Laboratory } \\ \text { ARTEMISS } & \text { Automatic Retrieval of Temperature and Emissivity using Spectral Smoothness } \\ \text { ARTISAC } & \text { ARTEMISS In-Scene Atmospheric Compensation } \\ \text { CIBR } & \text { continuum interpolated band ratio } \\ \text { CPU } & \text { central processing unit } \\ \text { ESN } & \text { Emissivity Spectrum Normalization } \\ \text { FPA } & \text { focal plane array } \\ \text { GPS } & \text { global positioing system } \\ \text { Hyper-Cam } & \text { hyperspectral camera } \\ \text { ISAC } & \text { In-Scene Atmospheric Correction } \\ \text { ISR } & \text { intelligence, surveillance and reconnaissance } \\ \text { ITAR } & \text { International Traffic in Arms Regulations } \\ \text { LUT } & \text { look-up table } \\ \text { LWIR } & \text { longwave infrared } \\ \text { MCT } & \text { mercury cadmium telluride } \\ \text { MET } & \text { meteorological } \\ \text { MODTRAN } & \text { Moderate Resolution Atmospheric Transmission } \\ \text { MMD } & \text { mean-maximum difference } \\ \text { MPI } & \text { message passing interface } \\ \text { MWIR } & \text { midwave infrared } \\ \text { NESR } & \text { noise equivalent spectral radiance } \\ \text { PDF } & \text { probability density function } \\ \end{array}$




$\begin{array}{ll}\text { PV } & \text { photovoltaic } \\ \text { QTES } & \text { Quick Temperature and Emissivity Separation } \\ \text { R\&D } & \text { research and development } \\ \text { RGB } & \text { red, green, blue } \\ \text { RMSE } & \text { root mean square error } \\ \text { SiAs } & \text { silicon arsenide } \\ \text { SNR } & \text { signal-to-noise ratio } \\ \text { SPICE } & \text { Spectral and Polarimetric Imagery Collection Experiment } \\ \text { TES } & \text { temperature-emissivity separation } \\ \text { TUD } & \text { transmission, up-welling, downwelling radiance }\end{array}$




\begin{tabular}{|c|c|c|c|}
\hline $\begin{array}{c}1 \\
(\mathrm{PDF})\end{array}$ & $\begin{array}{l}\text { DEFENSE TECH INFO CTR } \\
\text { ATTN DTIC OCA }\end{array}$ & $\begin{array}{c}1 \\
(\mathrm{PDF})\end{array}$ & $\begin{array}{l}\text { PICATINNY ARSENAL } \\
\text { ATTN J MICHALSON }\end{array}$ \\
\hline $\begin{array}{c}2 \\
(\mathrm{PDF})\end{array}$ & $\begin{array}{l}\text { US ARMY RSRCH LABORATORY } \\
\text { ATTN IMAL HRA MAIL \& } \\
\text { RECORDS MGMT } \\
\text { ATTN RDRL CIO LL TECHL LIB }\end{array}$ & $\begin{array}{c}2 \\
(\mathrm{PDF})\end{array}$ & $\begin{array}{l}\text { US ARMY ABERDEEN TEST } \\
\text { CENTER } \\
\text { ATTN TEDT AT WFT F CARLEN } \\
\text { ATTN CSTE DTC AT TC N } \\
\text { D L JENNINGS }\end{array}$ \\
\hline $\begin{array}{c}1 \\
(\mathrm{PDF})\end{array}$ & $\begin{array}{l}\text { GOVT PRNTG OFC } \\
\text { ATTN A MALHOTRA }\end{array}$ & $\begin{array}{c}12 \\
\text { (PDF) }\end{array}$ & $\begin{array}{l}\text { US ARMY AMDEC } \\
\text { ATTN R BURNS }\end{array}$ \\
\hline $\begin{array}{c}1 \\
(\mathrm{PDF})\end{array}$ & $\begin{array}{l}\text { DARPA } \\
\text { ATTN PM OF HEAT UPTOP } \\
\text { PROGRAM }\end{array}$ & & $\begin{array}{l}\text { ATTN C HESTER } \\
\text { ATTN C WALLACE } \\
\text { ATTN H EVERITT } \\
\text { ATTN J BUFORD }\end{array}$ \\
\hline $\begin{array}{c}1 \\
(\mathrm{PDF})\end{array}$ & $\begin{array}{l}\text { DEFENSE RESEARCH AND } \\
\text { DEVELOPMENT CANADA } \\
\text { VALCARTIER } \\
\text { ATTN J-M THERIAULT }\end{array}$ & & $\begin{array}{l}\text { ATTN J MILLS } \\
\text { ATTN K BRYANT } \\
\text { ATTN L LEVITT } \\
\text { ATTN M HEIMBECK } \\
\text { ATTN P RUFFIN }\end{array}$ \\
\hline $\begin{array}{c}1 \\
(\mathrm{PDF})\end{array}$ & $\begin{array}{l}\text { NGA } \\
\text { ATTN R S RAND }\end{array}$ & & $\begin{array}{l}\text { ATTN S VANSTONE } \\
\text { ATTN T WILKERSON }\end{array}$ \\
\hline $\begin{array}{c}1 \\
(\mathrm{PDF})\end{array}$ & $\begin{array}{l}\text { AED } \\
\text { ATTN B DEAR }\end{array}$ & $\begin{array}{c}1 \\
(\mathrm{PDF})\end{array}$ & $\begin{array}{l}\text { US ARMY AMFDEC } \\
\text { ATTN T LUM }\end{array}$ \\
\hline $\begin{array}{c}1 \\
(\mathrm{PDF})\end{array}$ & $\begin{array}{l}\text { APACHE RDR \& VIDEO-LINKS } \\
\text { ATTN R BRUNS }\end{array}$ & $\begin{array}{c}1 \\
(\mathrm{PDF})\end{array}$ & $\begin{array}{l}\text { US ARMY AVIATION \& MIS RD\&E } \\
\text { CMND } \\
\text { ATTN R HUBBARD }\end{array}$ \\
\hline $\begin{array}{c}1 \\
(\mathrm{PDF})\end{array}$ & $\begin{array}{l}\text { ARMY FW PMO } \\
\text { ATTN B SOLOMON }\end{array}$ & $\begin{array}{c}1 \\
(\mathrm{PDF})\end{array}$ & $\begin{array}{l}\text { US ARMY ERDC } \\
\text { ATTN J FUREY }\end{array}$ \\
\hline $\begin{array}{c}1 \\
(\mathrm{PDF})\end{array}$ & $\begin{array}{l}\text { AVCOM } \\
\text { ATTN AMSAM-RD-WS-PL } \\
\text { W DAVENPORT }\end{array}$ & $\begin{array}{c}1 \\
(\mathrm{PDF})\end{array}$ & $\begin{array}{l}\text { US ARMY ERDU } \\
\text { ATTN R GOODSON }\end{array}$ \\
\hline $\begin{array}{c}1 \\
(\mathrm{PDF})\end{array}$ & $\begin{array}{l}\text { CDR US ARMY TACOM ARDEC } \\
\text { ATTN RDAR MEF S G MINER }\end{array}$ & $\begin{array}{c}3 \\
(\mathrm{PDF})\end{array}$ & $\begin{array}{l}\text { US ARMY MAT SYS ANALYSIS } \\
\text { ACTVTY } \\
\text { ATTN AMSRD AMS SC }\end{array}$ \\
\hline $\begin{array}{c}1 \\
(\mathrm{PDF})\end{array}$ & $\begin{array}{l}\text { DYNETICS, INC. } \\
\text { ATTN M GRAVES }\end{array}$ & & $\begin{array}{l}\text { G KISTNER } \\
\text { ATTN AMSRD AMS SC J MAZZ } \\
\text { ATTN AMSRD AMS SC }\end{array}$ \\
\hline $\begin{array}{c}1 \\
(\mathrm{PDF})\end{array}$ & $\begin{array}{l}\text { KORD TECHNOLOGIES, INC. } \\
\text { ATTN C FARLOW }\end{array}$ & & R WHEELER \\
\hline $\begin{array}{c}1 \\
(\mathrm{PDF})\end{array}$ & $\begin{array}{l}\text { NMIC-ONI } \\
\text { ATTN L CHRISTEL }\end{array}$ & $\begin{array}{c}1 \\
(\mathrm{PDF})\end{array}$ & $\begin{array}{l}\text { US ARMY NVESD } \\
\text { ATTN G WHITTIER }\end{array}$ \\
\hline $\begin{array}{c}1 \\
(\mathrm{PDF})\end{array}$ & $\begin{array}{l}\text { OTC, INC/PM FIXED WING } \\
\text { ATTN J ICENOGLE }\end{array}$ & $\begin{array}{c}3 \\
(\mathrm{PDF})\end{array}$ & $\begin{array}{l}\text { US ARMY RDECOM AMRDEC } \\
\text { ATTN AMSRD AMR SG IP } \\
\text { H F ANDERSON } \\
\text { ATTN AMSRD AMR SG K RISKO }\end{array}$ \\
\hline 2 & $\begin{array}{l}\text { PACIFIC NORTHWEST NATIONAL } \\
\text { LAB }\end{array}$ & & $\begin{array}{l}\text { ATTN AMSRD AMR SG } \\
\text { W PITTMAN }\end{array}$ \\
\hline
\end{tabular}




\begin{tabular}{|c|c|c|c|}
\hline \multirow[t]{2}{*}{$\begin{array}{c}4 \\
(\mathrm{PDF})\end{array}$} & $\begin{array}{l}\text { US ARMY RDECOM ARDEC } \\
\text { ATTN AMSRD AAR AER } \\
\text { B SMITH }\end{array}$ & $\begin{array}{c}1 \\
(\mathrm{PDF})\end{array}$ & $\begin{array}{l}\text { COMMANDER } \\
\text { USAISEC } \\
\text { ATTN AMSEL TD BLAU }\end{array}$ \\
\hline & $\begin{array}{l}\text { ATTN AMSRD AAR MEF S } \\
\text { M WOOLLY } \\
\text { ATTN AMSRD AAR MEF S } \\
\text { P WILLSON } \\
\text { ATTN RDAR MEF S J ROMANO }\end{array}$ & $\begin{array}{c}4 \\
(\mathrm{PDF})\end{array}$ & $\begin{array}{l}\text { USASMDC/ARSTRAT } \\
\text { ATTN E KIKER } \\
\text { ATTN K BLANKENSHIP } \\
\text { ATTN R UPTON } \\
\text { ATTN S MCRAE }\end{array}$ \\
\hline $\begin{array}{c}4 \\
(\mathrm{PDF})\end{array}$ & $\begin{array}{l}\text { US ARMY RDECOM CERDEC } \\
\text { NVESD } \\
\text { ATTN AMSRD CER NV OD } \\
\text { S MORRISON } \\
\text { ATTN AMSRD CER NV SPPD IST } \\
\text { H KLING }\end{array}$ & $\begin{array}{c}3 \\
(\mathrm{PDF})\end{array}$ & $\begin{array}{l}\text { NAV RSRCH LAB } \\
\text { ATTN D BRADSHAW } \\
\text { ATTN M KAPPUS } \\
\text { ATTN W HUO }\end{array}$ \\
\hline & $\begin{array}{l}\text { ATTN AMSRD CER NV SPPD IST } \\
\text { S DUNBAR } \\
\text { ATTN AMSRD CER NV ST }\end{array}$ & $\begin{array}{c}1 \\
(\mathrm{PDF})\end{array}$ & $\begin{array}{l}\text { NAV UNDERSEA WARFARE CTR } \\
\text { ATTN R GUDZ }\end{array}$ \\
\hline $\begin{array}{c}1 \\
\text { (PDF) }\end{array}$ & $\begin{array}{l}\text { US ARMY RDECOM TARDEC } \\
\text { ATTN AMSRD TAR R }\end{array}$ & $\begin{array}{c}1 \\
(\mathrm{PDF})\end{array}$ & $\begin{array}{l}\text { US NVESD } \\
\text { ATTN SPPD STAB } \\
\text { L RAMBOYONG }\end{array}$ \\
\hline & $\begin{array}{l}\text { G R GERHART } \\
\text { US ARMY RSRCH LAB }\end{array}$ & $\begin{array}{c}2 \\
(\mathrm{PDF})\end{array}$ & $\begin{array}{l}\text { AEROSPACE TESTING ALLIANCE } \\
\text { ATTN H LOWRY } \\
\text { ATTN J OGLE }\end{array}$ \\
\hline (PDF) & $\begin{array}{l}\text { ATTN AMSRD ARL RO EL } \\
\text { W SMITH } \\
\text { ATTN AMSRD ARL RO M } \\
\text { D ARNEY } \\
\text { ATTN AMSRD ARL RO MI } \\
\text { R ZACHERY }\end{array}$ & $\begin{array}{c}2 \\
(\mathrm{PDF})\end{array}$ & $\begin{array}{l}\text { AIR FORCE INST OF } \\
\text { TECHNOLOGY } \\
\text { ATTN C BOREL-DONOHU } \\
\text { ATTN E CARLSON }\end{array}$ \\
\hline $\begin{array}{c}1 \\
(\mathrm{PDF})\end{array}$ & $\begin{array}{l}\text { US ARMY SOLDIER \& } \\
\text { BIOLOGICAL CHEM CTR } \\
\text { ATTN AMSRD ECB RT DE } \\
\text { W LOEROP }\end{array}$ & $\begin{array}{c}1 \\
(\mathrm{PDF}) \\
1 \\
(\mathrm{PDF})\end{array}$ & $\begin{array}{l}\text { ATA } \\
\text { ATTN S STEELY } \\
\text { HC DIA } \\
\text { ATTN DIA/DTT-2 } \\
\text { R RICHARDSON }\end{array}$ \\
\hline $\begin{array}{c}1 \\
(\mathrm{PDF})\end{array}$ & $\begin{array}{l}\text { US ARMY SPACE \& MIS DEFENSE } \\
\text { CMND/AMRSTRAT } \\
\text { ATTN S SMITH }\end{array}$ & $\begin{array}{c}1 \\
(\mathrm{PDF})\end{array}$ & $\begin{array}{l}\text { USAR-AEDC } \\
\text { ATTN B STEWART }\end{array}$ \\
\hline $\begin{array}{c}1 \\
(\mathrm{PDF})\end{array}$ & $\begin{array}{l}\text { US ARMY US AMY DOD CIV PM } \\
\text { FW } \\
\text { ATTN E WOODS }\end{array}$ & $\begin{array}{c}1 \\
(\mathrm{PDF})\end{array}$ & $\begin{array}{l}\text { USN } \\
\text { ATTN J HERMAN }\end{array}$ \\
\hline $\begin{array}{c}1 \\
(\mathrm{PDF})\end{array}$ & $\begin{array}{l}\text { USACE } \\
\text { ATTN J MORGAN }\end{array}$ & $\begin{array}{c}1 \\
(\mathrm{PDF})\end{array}$ & $\begin{array}{l}\text { DEPARTMENT OF ENERGY } \\
\text { ATTN V FRANQUES }\end{array}$ \\
\hline $\begin{array}{c}1 \\
\text { (PDF) }\end{array}$ & $\begin{array}{l}\text { USACE ERDC } \\
\text { ATTN T BERRY }\end{array}$ & $\begin{array}{c}1 \\
(\mathrm{PDF})\end{array}$ & $\begin{array}{l}\text { HC DOE/NA-22 } \\
\text { ATTN V FRANQUES }\end{array}$ \\
\hline & & $\begin{array}{c}1 \\
(\mathrm{PDF})\end{array}$ & $\begin{array}{l}\text { NATIONAL SECURITY } \\
\text { TECHNOLOGIES, LLC } \\
\text { ATTN M O'NEILL }\end{array}$ \\
\hline
\end{tabular}




\begin{tabular}{|c|c|c|c|}
\hline $\begin{array}{c}1 \\
(\mathrm{PDF})\end{array}$ & $\begin{array}{l}\text { NSTEC } \\
\text { ATTN P SAWYER }\end{array}$ & $\begin{array}{c}1 \\
(\mathrm{PDF})\end{array}$ & $\begin{array}{l}\text { UNIV OF ILLINOIS } \\
\text { ATTN P KUMAS }\end{array}$ \\
\hline $\begin{array}{c}1 \\
(\mathrm{PDF})\end{array}$ & $\begin{array}{l}\text { LAWRENCE LIVERMORE NATL } \\
\text { LAB } \\
\text { ATTN J LAWSON }\end{array}$ & $\begin{array}{c}1 \\
(\mathrm{PDF})\end{array}$ & $\begin{array}{l}\text { UTAH STATE UNIV } \\
\text { ATTN J GUNTHER }\end{array}$ \\
\hline $\begin{array}{c}3 \\
(\mathrm{PDF})\end{array}$ & $\begin{array}{l}\text { SANDIA NATL LAB } \\
\text { ATTN J JONES } \\
\text { ATTN T KULP } \\
\text { ATTN T REICHARDT }\end{array}$ & $\begin{array}{c}1 \\
(\mathrm{PDF})\end{array}$ & $\begin{array}{l}\text { VIRGINIA POLYTECHNIC INST } \\
\text { AND STATE UNIV } \\
\text { ATTN M TERESI } \\
\text { VIRGINIA TECH } \\
\text { ATTN M UMANSKY }\end{array}$ \\
\hline $\begin{array}{c}1 \\
(\mathrm{PDF})\end{array}$ & $\begin{array}{l}\text { DEPT OF COMMERCE/NIST } \\
\text { ATTN J RICE }\end{array}$ & $\begin{array}{c}2 \\
(\mathrm{PDF})\end{array}$ & $\begin{array}{l}\text { MESH.INC } \\
\text { ATTN L GRIM }\end{array}$ \\
\hline $\begin{array}{c}1 \\
(\mathrm{PDF})\end{array}$ & $\begin{array}{l}\text { LANDMARK TECHNOLOGY } \\
\text { ATTN R JONES }\end{array}$ & & ATTN T GRUBER \\
\hline $\begin{array}{c}1 \\
(\mathrm{PDF})\end{array}$ & $\begin{array}{l}\text { NASA MSFC } \\
\text { ATTN J CASAS }\end{array}$ & $\begin{array}{c}1 \\
(\mathrm{PDF})\end{array}$ & $\begin{array}{l}\text { ARETE ASSOCIATES } \\
\text { ATTN B HOOPER }\end{array}$ \\
\hline $\begin{array}{c}1 \\
(\mathrm{PDF})\end{array}$ & $\begin{array}{l}\text { NSTEC } \\
\text { ATTN D BERRY }\end{array}$ & $\begin{array}{c}1 \\
(\mathrm{PDF})\end{array}$ & $\begin{array}{l}\text { CACI TECHNOLOGIES, INC } \\
\text { ATTN H HIRSCH }\end{array}$ \\
\hline $\begin{array}{c}2 \\
(\mathrm{PDF})\end{array}$ & $\begin{array}{l}\text { US GOVERNMENT, NASA } \\
\text { ATTN V VANDERBILT }\end{array}$ & $\begin{array}{c}1 \\
(\mathrm{PDF})\end{array}$ & $\begin{array}{l}\text { CHARLES STARK DRAPER LAB } \\
\text { ATTN D LANDIS }\end{array}$ \\
\hline $\begin{array}{c}1 \\
(\mathrm{PDF})\end{array}$ & $\begin{array}{l}\text { ATTN A GOLDBERG } \\
\text { (CCNY) CITY } \\
\text { ATTN A GILERSO }\end{array}$ & $\begin{array}{c}2 \\
(\mathrm{PDF})\end{array}$ & $\begin{array}{l}\text { DYNETICS, INC } \\
\text { ATTN J DAWSON } \\
\text { ATTN P BURKE }\end{array}$ \\
\hline $\begin{array}{c}1 \\
(\mathrm{PDF})\end{array}$ & $\begin{array}{l}\text { COLLEGE OF NEW YORK } \\
\text { ATTN A GOLDBERG }\end{array}$ & $\begin{array}{c}1 \\
(\mathrm{PDF})\end{array}$ & $\begin{array}{l}\text { HINDS INSTRUMENTS } \\
\text { ATTN L HIRSCHY }\end{array}$ \\
\hline $\begin{array}{c}1 \\
(\mathrm{PDF})\end{array}$ & $\begin{array}{l}\text { MONTANA STATE UNIV } \\
\text { ATTN N PUST }\end{array}$ & $\begin{array}{c}1 \\
(\mathrm{PDF})\end{array}$ & $\begin{array}{l}\text { IERUS TECHNOLOGIES } \\
\text { ATTN C PERSONS }\end{array}$ \\
\hline $\begin{array}{c}1 \\
(\mathrm{PDF})\end{array}$ & $\begin{array}{l}\text { ROCHESTER INST OF } \\
\text { TECHNOLOGY } \\
\text { ATTN S BROWN }\end{array}$ & $\begin{array}{c}3 \\
(\mathrm{PDF})\end{array}$ & $\begin{array}{l}\text { L-3 COMMUNICATIONS IOS-SSG } \\
\text { ATTN J ROBICHAUD } \\
\text { ATTN D LEHAN } \\
\text { ATTN J MASON }\end{array}$ \\
\hline $\begin{array}{c}4 \\
(\mathrm{PDF})\end{array}$ & $\begin{array}{l}\text { THE UNIV OF ALABAMA- } \\
\text { HUNTSVILLE } \\
\text { ATTN S GRAVES } \\
\text { ATTN B ROBINSON } \\
\text { ATTN J GUO }\end{array}$ & $\begin{array}{c}3 \\
(\mathrm{PDF})\end{array}$ & $\begin{array}{l}\text { LOCKHEAD MARTIN } \\
\text { ATTN H DANIEL } \\
\text { ATTN C HOLDEN } \\
\text { ATTN D TWEDE }\end{array}$ \\
\hline & ATTN S TANNER & $\begin{array}{c}1 \\
(\mathrm{PDF})\end{array}$ & $\begin{array}{l}\text { PACIFIC ADVANCED } \\
\text { TECHNOLOGY }\end{array}$ \\
\hline $\begin{array}{c}1 \\
(\mathrm{PDF})\end{array}$ & $\begin{array}{l}\text { THE UNIVERSITY OF ALABAMA } \\
\text { ATTN T BERENDES }\end{array}$ & & ATTN M HINNRICHS \\
\hline $\begin{array}{c}1 \\
(\mathrm{PDF})\end{array}$ & $\begin{array}{l}\text { UNIV OF ARIZONA } \\
\text { ATTN S MCCLAIN }\end{array}$ & $\begin{array}{c}2 \\
(\mathrm{PDF})\end{array}$ & $\begin{array}{l}\text { POLARIS SENSOR TECHNOLOGIE } \\
\text { ATTN L PEZZANITI } \\
\text { ATTN A LOMPADO }\end{array}$ \\
\hline $\begin{array}{c}1 \\
(\mathrm{PDF})\end{array}$ & $\begin{array}{l}\text { UNIV OF CENTRAL FLORIDA } \\
\text { ATTN T KOHLGRAF-OWENS }\end{array}$ & $\begin{array}{c}1 \\
(\mathrm{PDF})\end{array}$ & $\begin{array}{l}\text { Q5 INNOVATIONS INC } \\
\text { ATTN J PLANT }\end{array}$ \\
\hline
\end{tabular}




$\begin{array}{cl}1 & \text { RAYTHEON/PRA } \\ \text { (PDF) } & \text { ATTN C-H AN } \\ 1 & \text { SPACE COMPUTER CORP } \\ (\mathrm{PDF}) & \text { ATTN B RATLIFF } \\ 1 & \text { SRI INRL } \\ (\mathrm{PDF}) & \text { ATTN C SCHWARTZ } \\ 3 & \text { TELEDYNE SCIENTIFIC } \\ (\mathrm{PDF}) & \text { COMPANY } \\ & \text { ATTN D-F GU } \\ & \text { ATTN J ZHOU } \\ & \text { ATTN Y LIAO } \\ 1 & \text { TELOPS } \\ \text { (PDF) } & \text { ATTN V FARLEY } \\ 1 & \text { US ARMY RSRCH LAB } \\ \text { (PDF) } & \text { ATTN RDRL WML A W OBERLE }\end{array}$

$\begin{array}{cl}1 & \text { DIRECTOR } \\ \text { (PDF) } & \text { US ARMY RSRCH LAB } \\ & \text { ATTN RDRL ROI C L DAI } \\ 12 & \text { US ARMY RSRCH LAB } \\ \text { (PDF) } & \text { ATTN RDRL CIE S A WETMORE } \\ & \text { ATTN RDRL CIE S K GURTON } \\ & \text { ATTN RDRL D T RUSSELL } \\ & \text { ATTN RDRL SEE E N GUPTA } \\ & \text { ATTN RDRL SES A N SROUR } \\ & \text { ATTN RDRL SES E D ROSARIO } \\ & \text { ATTN RDRL SES E H KWON } \\ & \text { ATTN RDRL SES E L A CHAN } \\ & \text { ATTN RDRL SES E M THIELKE } \\ & \text { ATTN RDRL SES E } \\ & \text { N NASRABADI } \\ \text { ATTN RDRL SES J EICKE } & \text { ATTN RDRL SES S M D'ONOFRIO }\end{array}$


INTENTIONALLY LEFT BLANK. 